\title{
Computationally Guided Tuning of Peptide-Conjugated Perylene Diimide Self-Assembly
}

Sayak Subhra Panda ${ }^{\dagger}$, Kirill Shmilovich`, Nicholas S. M. Herringer", Nicolas Marin ${ }^{\dagger}$, Andrew L.

Ferguson", and John D. Tovar ${ }^{*}, \dagger$,

${ }^{\dagger}$ Department of Chemistry, Johns Hopkins University, 3400 North Charles Street, Baltimore, Maryland 21218, United States.

$\$$ Department of Materials Science and Engineering, Johns Hopkins University, 3400 North Charles Street, Baltimore, Maryland 21218, United States.

^ Pritzker School of Molecular Engineering, University of Chicago, 5640 South Ellis Avenue, Chicago, Illinois, 60637, United States.

*Corresponding author email: tovar@jhu.edu

\section{Table of Contents}

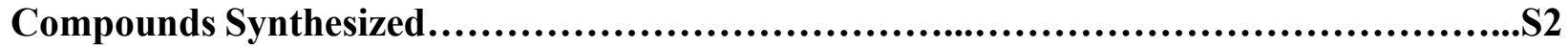

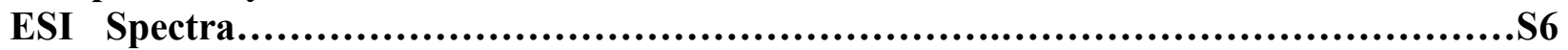

Analytical HPLC Traces...................................................................

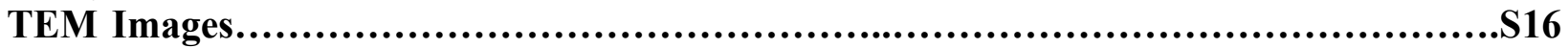

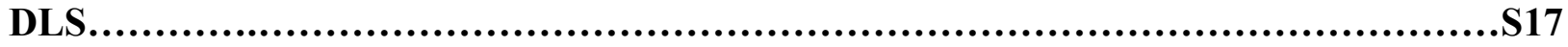

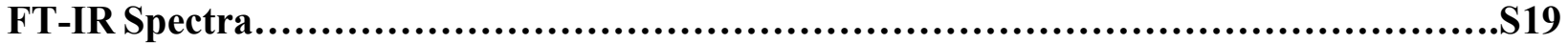

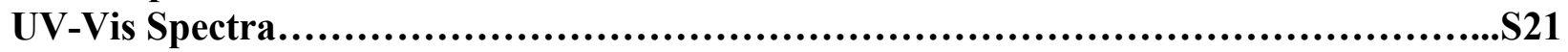

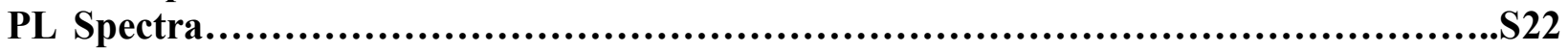

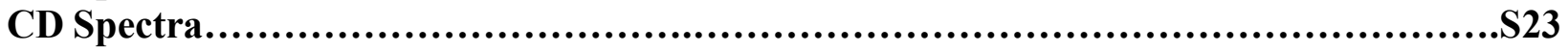




\section{Compounds Synthesized:}

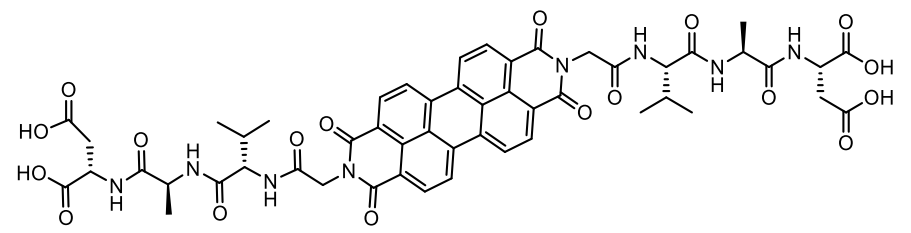

HO-DAVG-PDI-GVAD-OH: Crude peptide was obtained as a black powder (0.010 mmol, 0.011 g, 20.6\% yield). Following HPLC purification, $0.008 \mathrm{mmol}, 0.009 \mathrm{~g}, 16.2 \%$ yield. MS (ESI) m/z $1113.3(\mathrm{M}+\mathrm{K}-2 \mathrm{H})^{-}\left(\right.$calc. 1113.3), m/z $1075.2(\mathrm{M}-\mathrm{H})^{-}\left(\right.$calc. 1075.4), m/z $537.2(\mathrm{M}-2 \mathrm{H})^{2-}($ calc. 537.2).

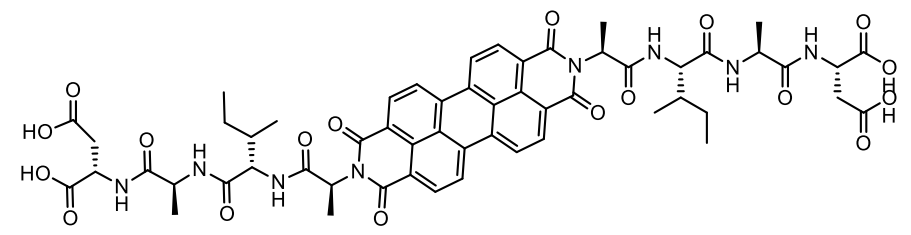

HO-DAIA-PDI-AIAD-OH: Crude peptide was obtained as a deep red powder (0.007 mmol, $0.008 \mathrm{~g}, 14.3 \%$ yield). Following HPLC purification, $0.005 \mathrm{mmol}, 0.006 \mathrm{~g}, 10.5 \%$ yield. MS (ESI)

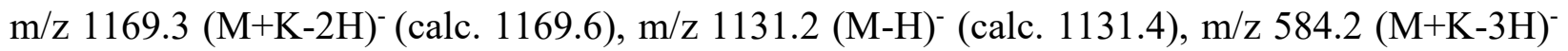
(calc. 584.2), m/z $565.3(\mathrm{M}-2 \mathrm{H})^{2-}($ calc. 565.2).

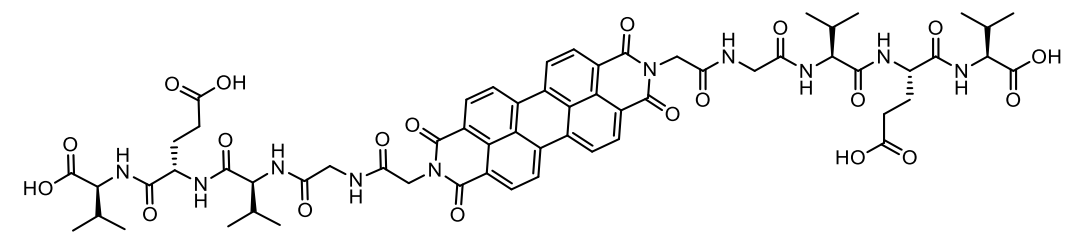

HO-VEVGG-PDI-GGVEV-OH: Crude peptide was obtained as a black powder (0.005 mmol, $0.008 \mathrm{~g}, 10.0 \%$ yield). Following HPLC purification, $0.002 \mathrm{mmol}, 0.003 \mathrm{~g}, 4.00 \%$ yield. MS (ESI) 
$\mathrm{m} / \mathrm{z} 1311.87(\mathrm{M}+\mathrm{K}-2 \mathrm{H})^{-}$(calc. 1312.45), m/z $1273.87(\mathrm{M}-\mathrm{H})^{-}$(calc. 1274.29), m/z 637.12 (M$2 \mathrm{H})^{2-}($ calc. 637.21).

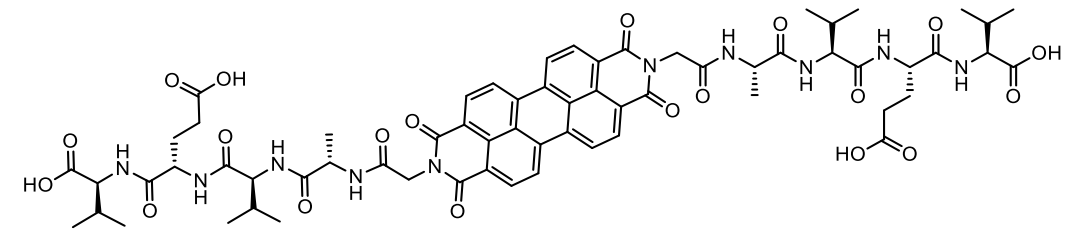

HO-VEVAG-PDI-GAVEV-OH: Crude peptide was obtained as a black powder (0.034 mmol, $0.045 \mathrm{~g}, 22.4 \%$ yield). Following HPLC purification, $0.015 \mathrm{mmol}, 0.021 \mathrm{~g}, 10.4 \%$ yield. MS (ESI) $\mathrm{m} / \mathrm{z} 1339.53(\mathrm{M}+\mathrm{K}-2 \mathrm{H})^{-}$(calc. 1340.35), m/z $650.85(\mathrm{M}-2 \mathrm{H})^{2-}($ calc. 651.67).

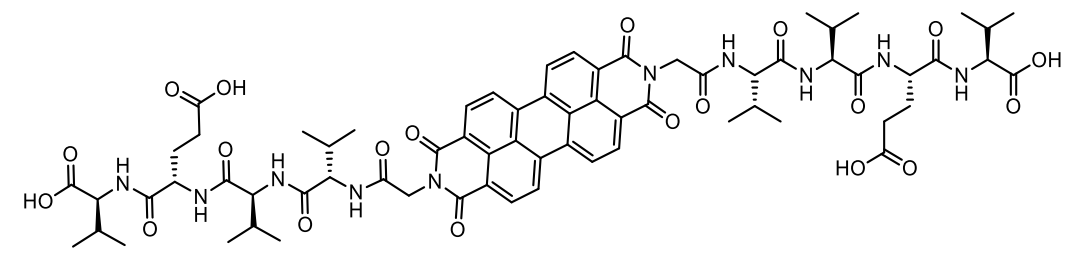

HO-VEVVG-PDI-GVVEV-OH: Crude peptide was obtained as a black powder (0.006 mmol, $0.009 \mathrm{~g}, 12.9 \%$ yield). Following HPLC purification, $0.004 \mathrm{mmol}, 0.006 \mathrm{~g}, 8.82 \%$ yield. MS (ESI) m/z $1395.58(\mathrm{M}+\mathrm{K}-2 \mathrm{H})^{-}$(calc. 1396.34), m/z $1357.66(\mathrm{M}-\mathrm{H})^{-}$(calc. 1358.45), m/z 678.85 (M$2 \mathrm{H})^{2-}($ calc. 678.22).

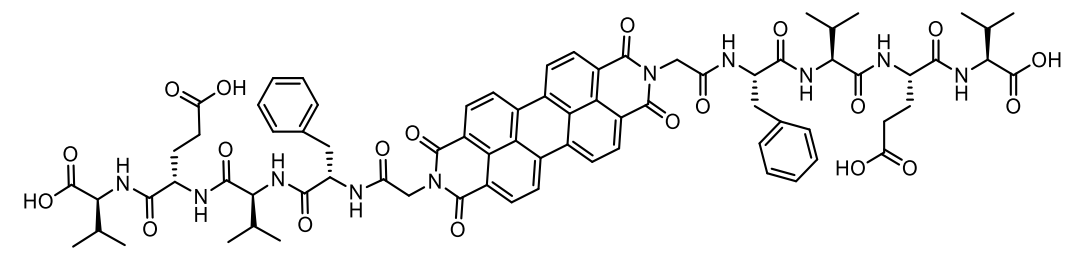

HO-VEVFG-PDI-GFVEV-OH: Crude peptide was obtained as a black powder (0.008 mmol, $0.012 \mathrm{~g}, 16.3 \%$ yield). Following HPLC purification, $0.006 \mathrm{mmol}, 0.009 \mathrm{~g}, 12.4 \%$ yield. MS (ESI) m/z $1492.61(\mathrm{M}+\mathrm{K}-2 \mathrm{H})^{-}$(calc. 1491.78), m/z $1454.66(\mathrm{M}-\mathrm{H})^{-}$(calc. 1455.54), m/z 727.16 (M2H) ${ }^{2-}$ (calc. 726.77). 


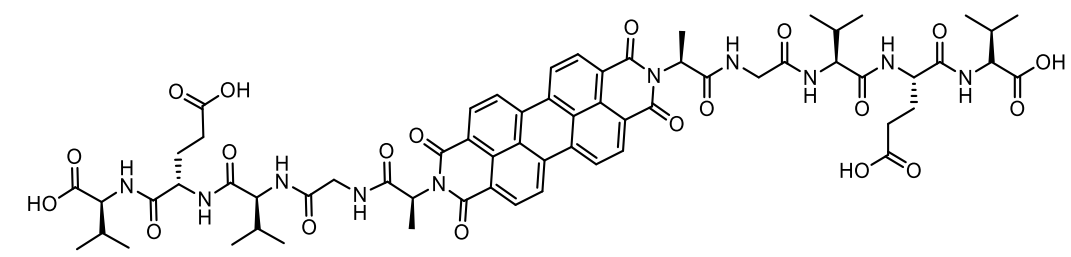

HO-VEVGA-PDI-AGVEV-OH: Crude peptide was obtained as a deep red powder (0.012 mmol, $0.015 \mathrm{~g}, 22.8 \%$ yield). Following HPLC purification, $0.008 \mathrm{mmol}, 0.010 \mathrm{~g}, 15.4 \%$ yield. MS (ESI) $\mathrm{m} / \mathrm{z} 1301.56(\mathrm{M}-\mathrm{H})^{-}\left(\right.$calc. 1302.35), m/z $650.84(\mathrm{M}-2 \mathrm{H})^{2-}($ calc. 651.68).

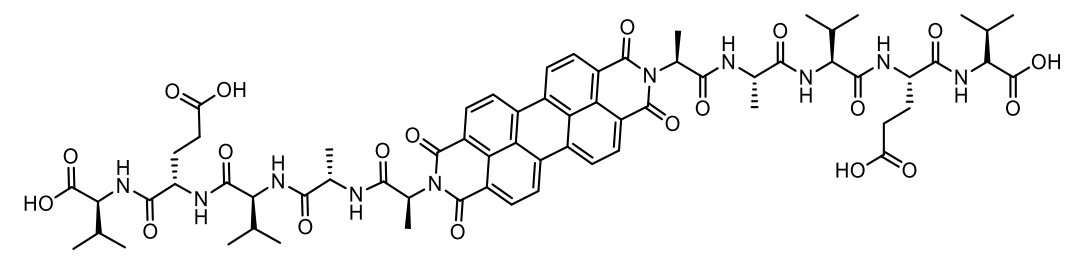

HO-VEVAA-PDI-AAVEV-OH: Crude peptide was obtained as a deep red powder (0.009 mmol, $0.012 \mathrm{~g}, 17.1 \%$ yield). Following HPLC purification, $0.006 \mathrm{mmol}, 0.009 \mathrm{~g}, 12.3 \%$ yield. MS (ESI)

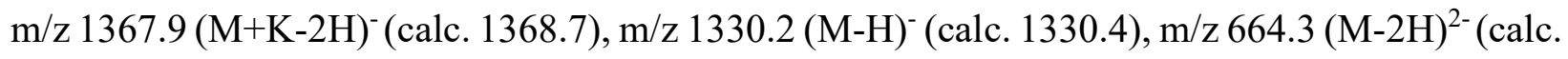
664.7).

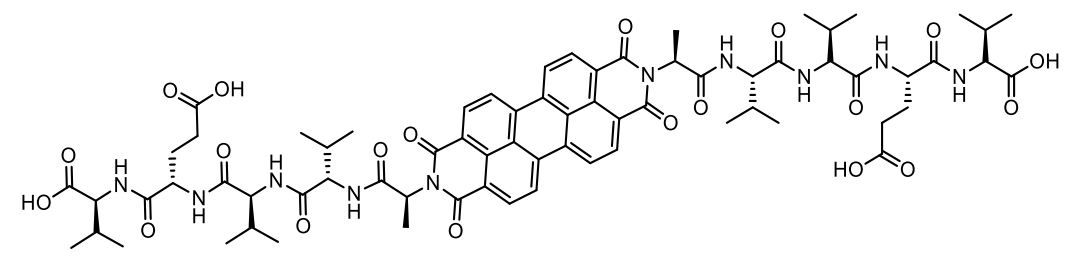

HO-VEVVA-PDI-AVVEV-OH: Crude peptide was obtained as a deep red powder (0.010 mmol, $0.014 \mathrm{~g}, 20.2 \%$ yield). Following HPLC purification, $0.007 \mathrm{mmol}, 0.009 \mathrm{~g}, 18.0 \%$ yield. MS (ESI)

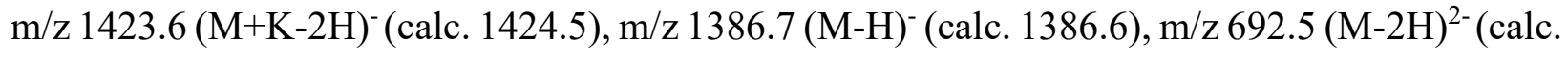
692.8). 


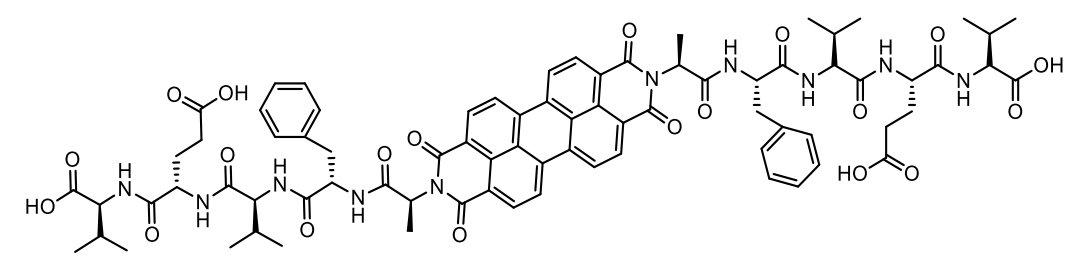

HO-VEVFA-PDI-AFVEV-OH: Crude peptide was obtained as a deep red powder (0.011 mmol, $0.016 \mathrm{~g}, 22.2 \%$ yield). Following HPLC purification, $0.009 \mathrm{mmol}, 0.013 \mathrm{~g}, 17.3 \%$ yield. MS (ESI) $\mathrm{m} / \mathrm{z} 1482.69(\mathrm{M}-\mathrm{H})^{-}\left(\right.$calc. 1482.60), m/z $741.23(\mathrm{M}-2 \mathrm{H})^{2-}($ calc. 741.80). 


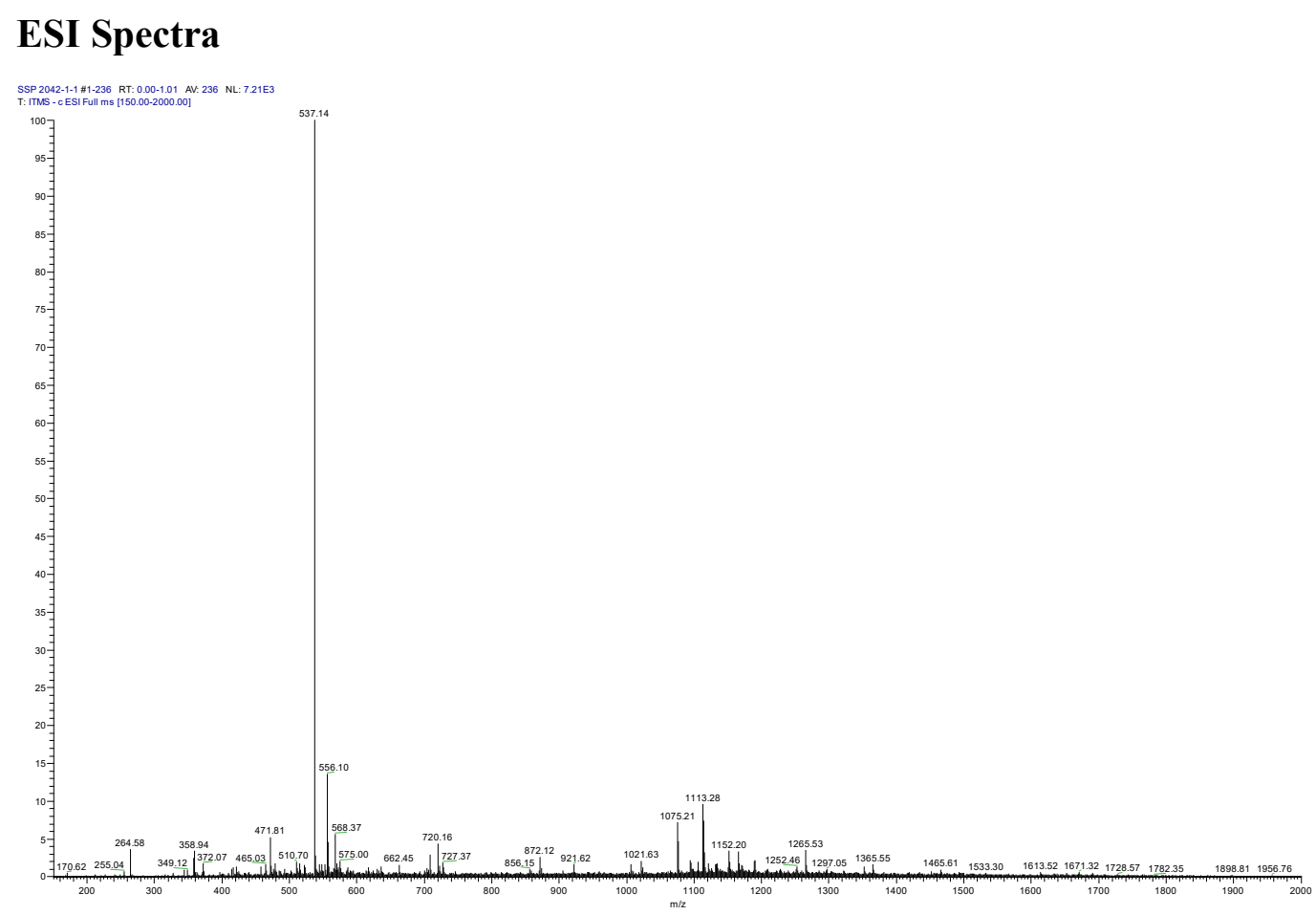

Figure S1. ESI- of DAVG-PDI-GVAD.

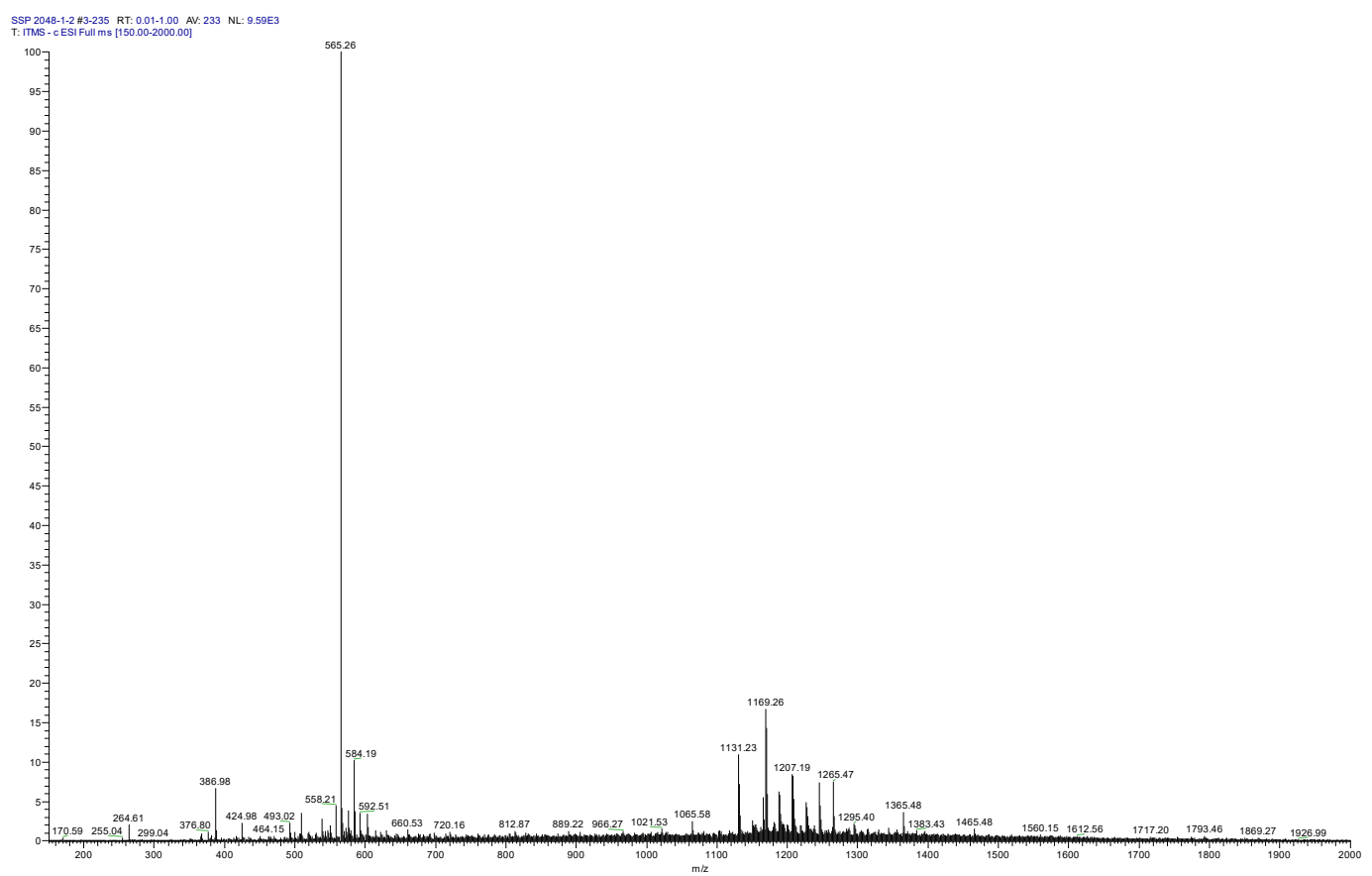

Figure S2. ESI- of DAIA-PDI-AIAD. 


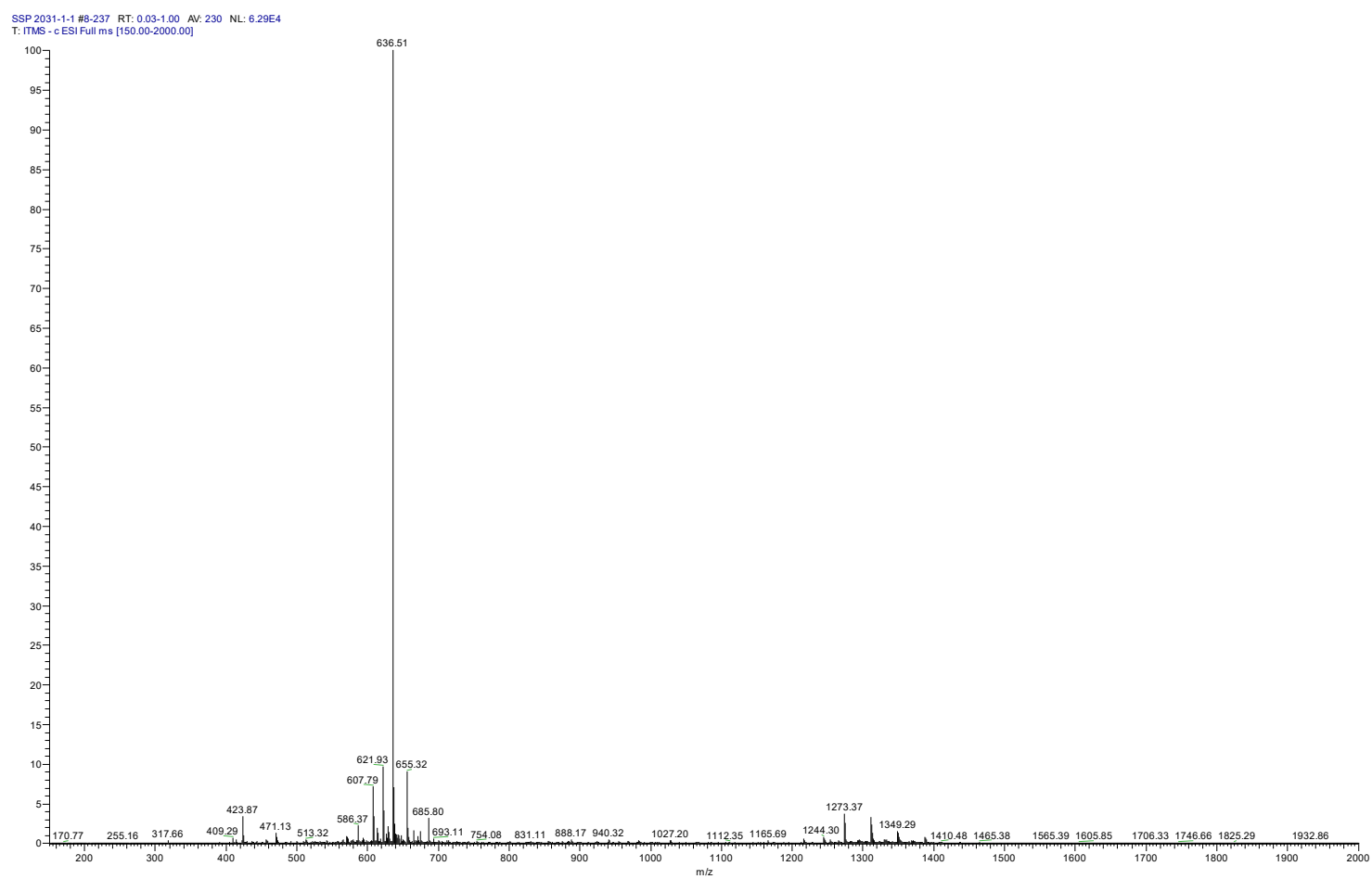

Figure S3. ESI- of VEVGG-PDI-GGVEV.

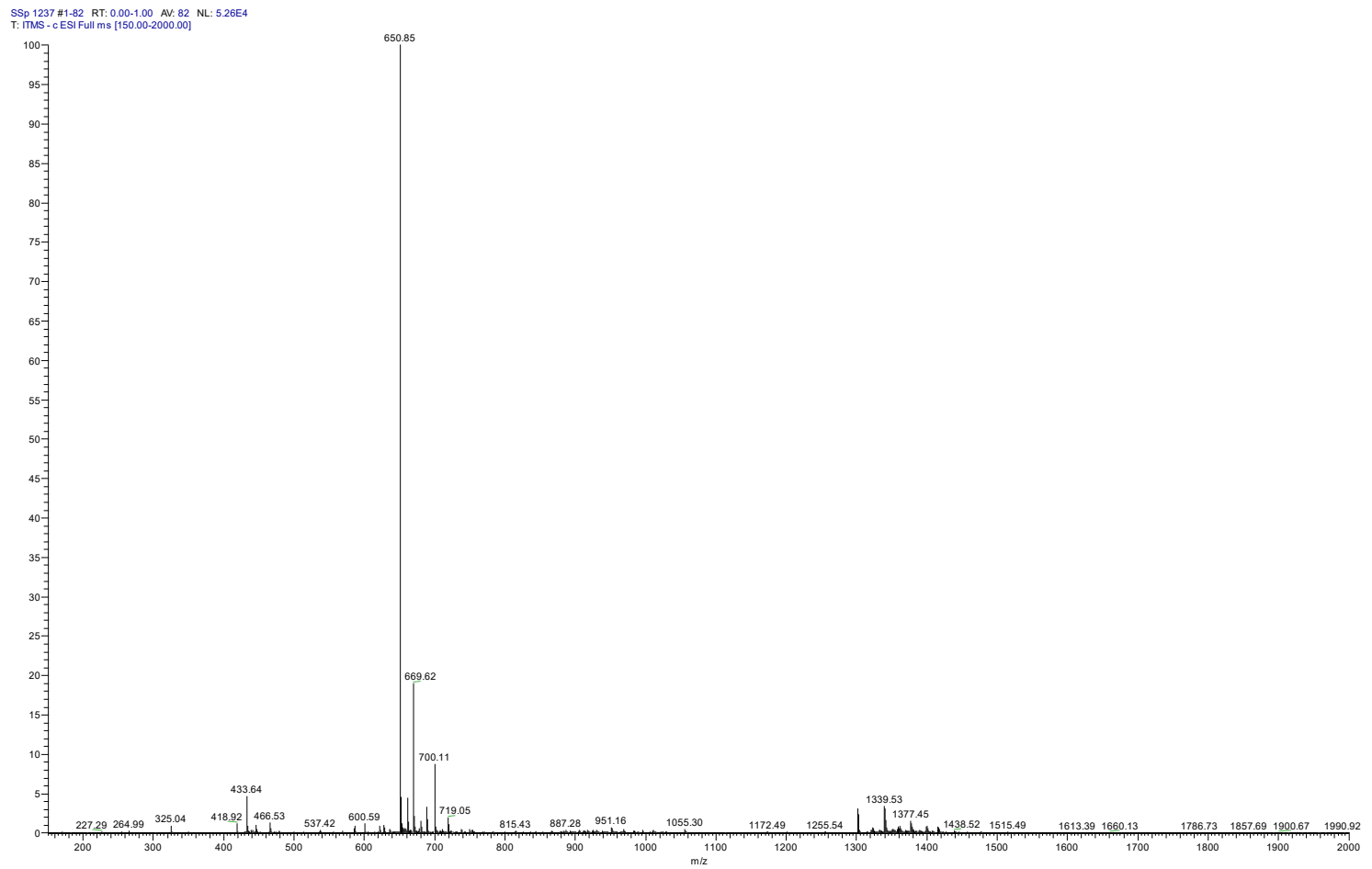

Figure S4. ESI- of VEVAG-PDI-GAVEV. 


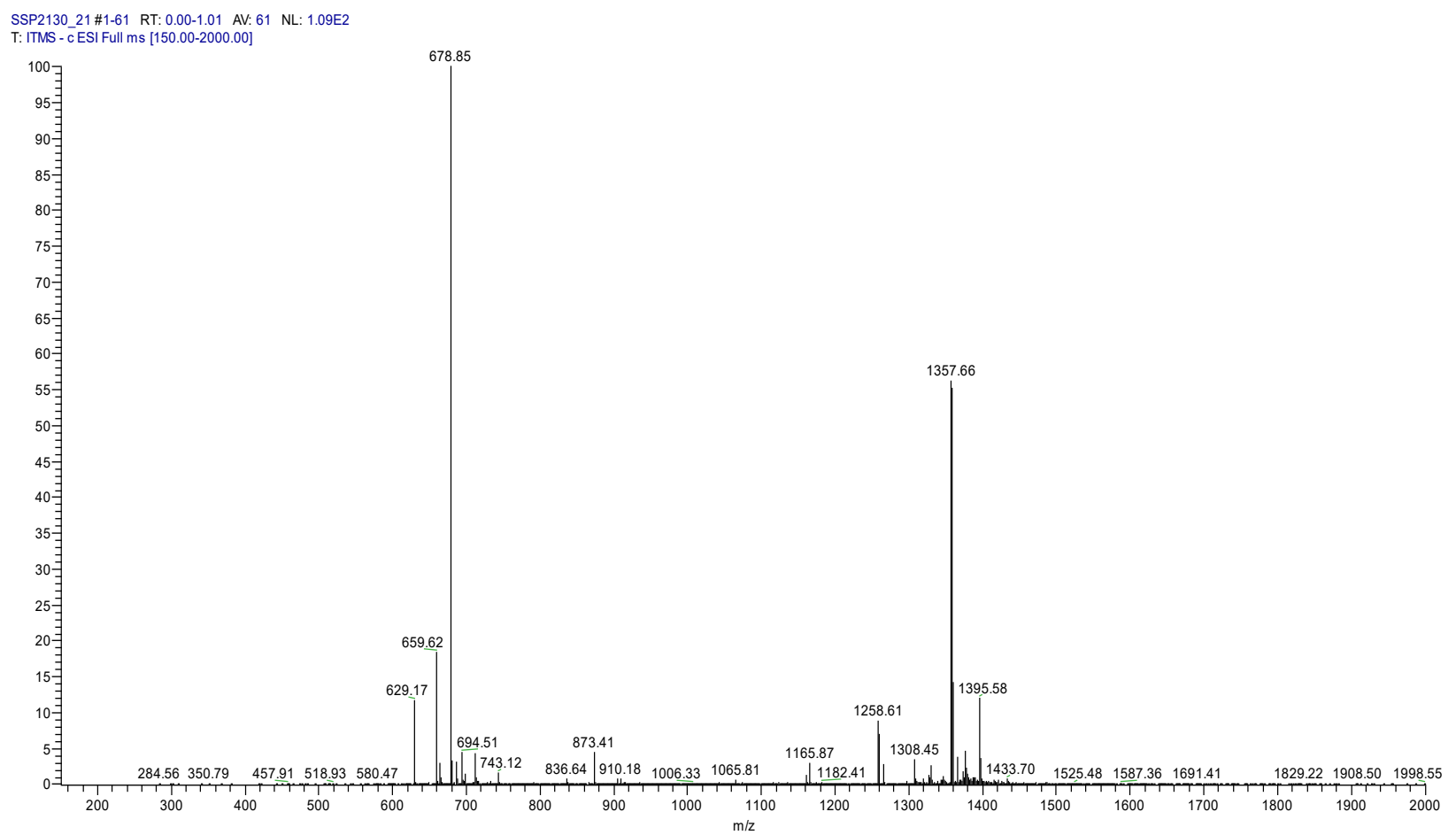

\section{Figure S5. ESI- of VEVVG-PDI-GVVEV.}

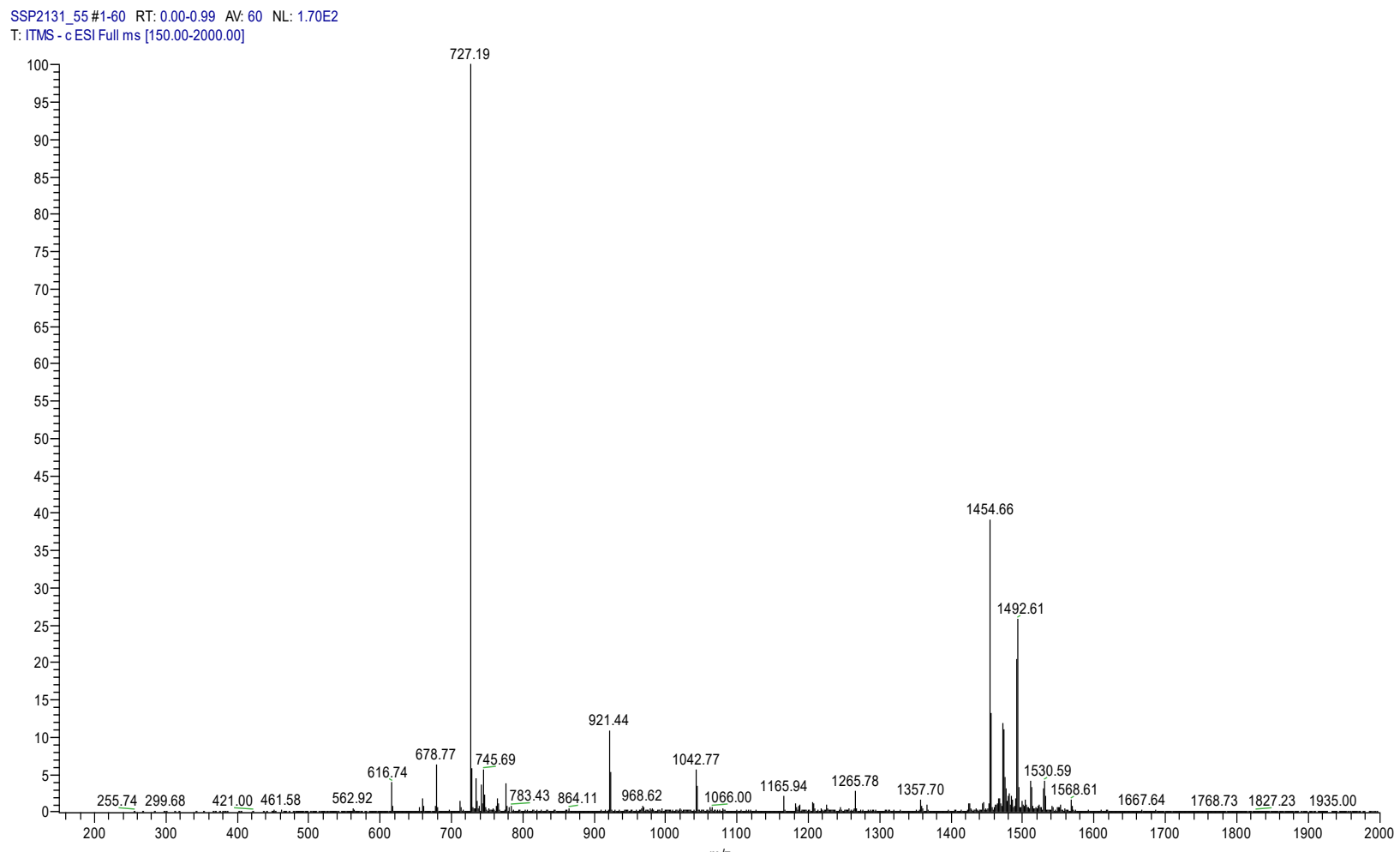

Figure S6. ESI- of VEVFG-PDI-GFVEV. 


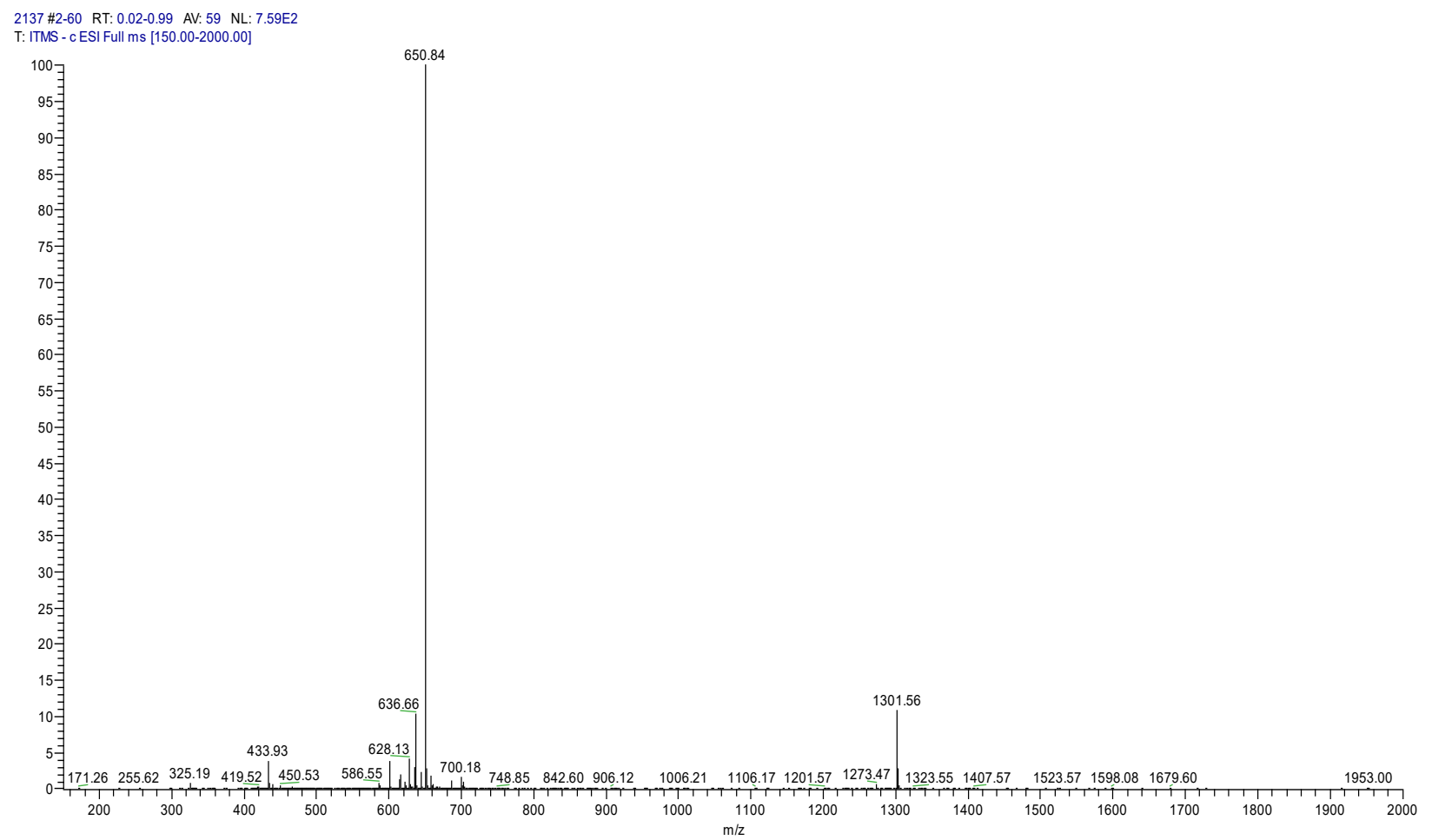

Figure S7. ESI- of VEVGA-PDI-AGVEV.

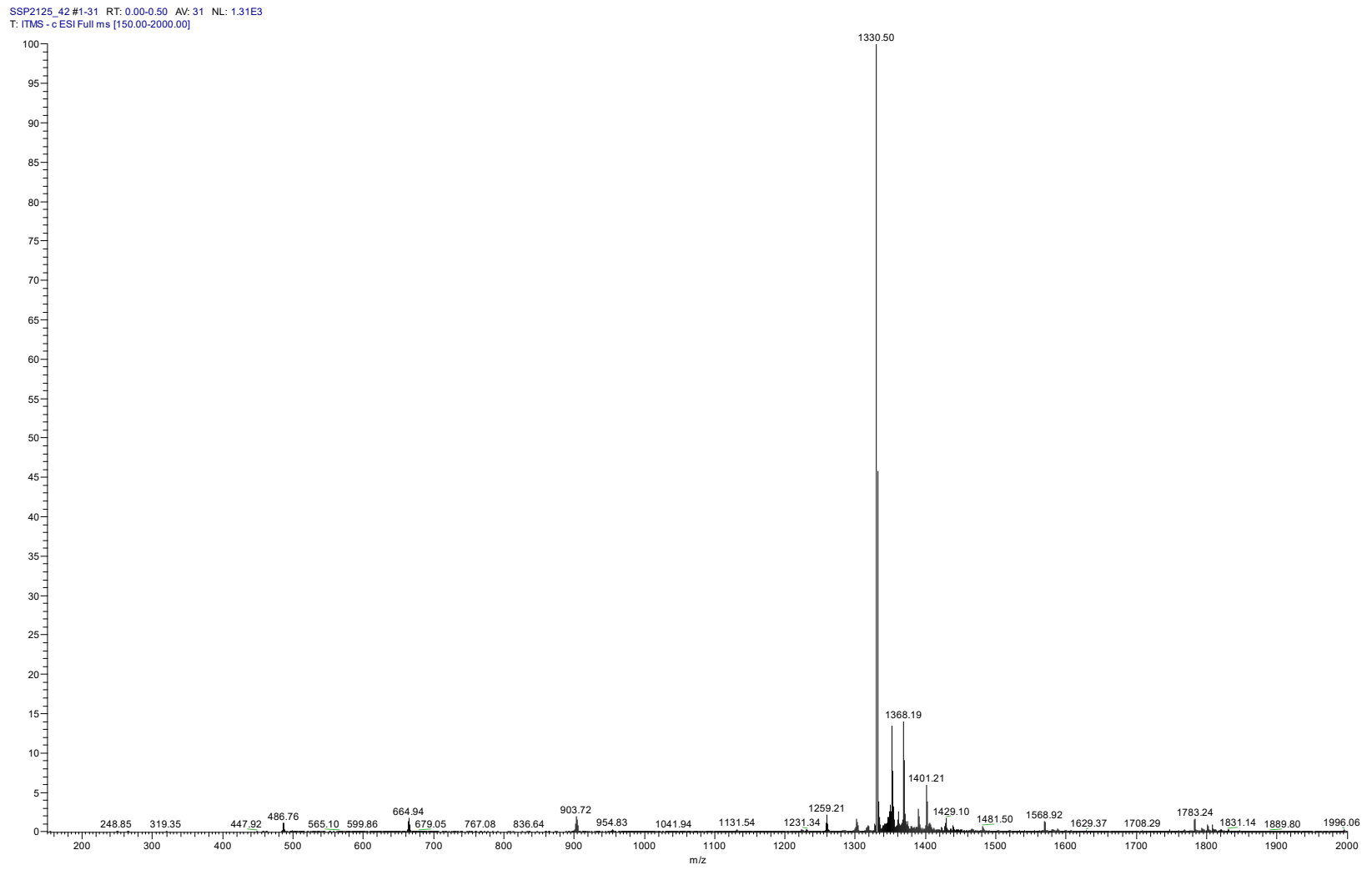

Figure S8. ESI- of VEVAA-PDI-AAVEV. 


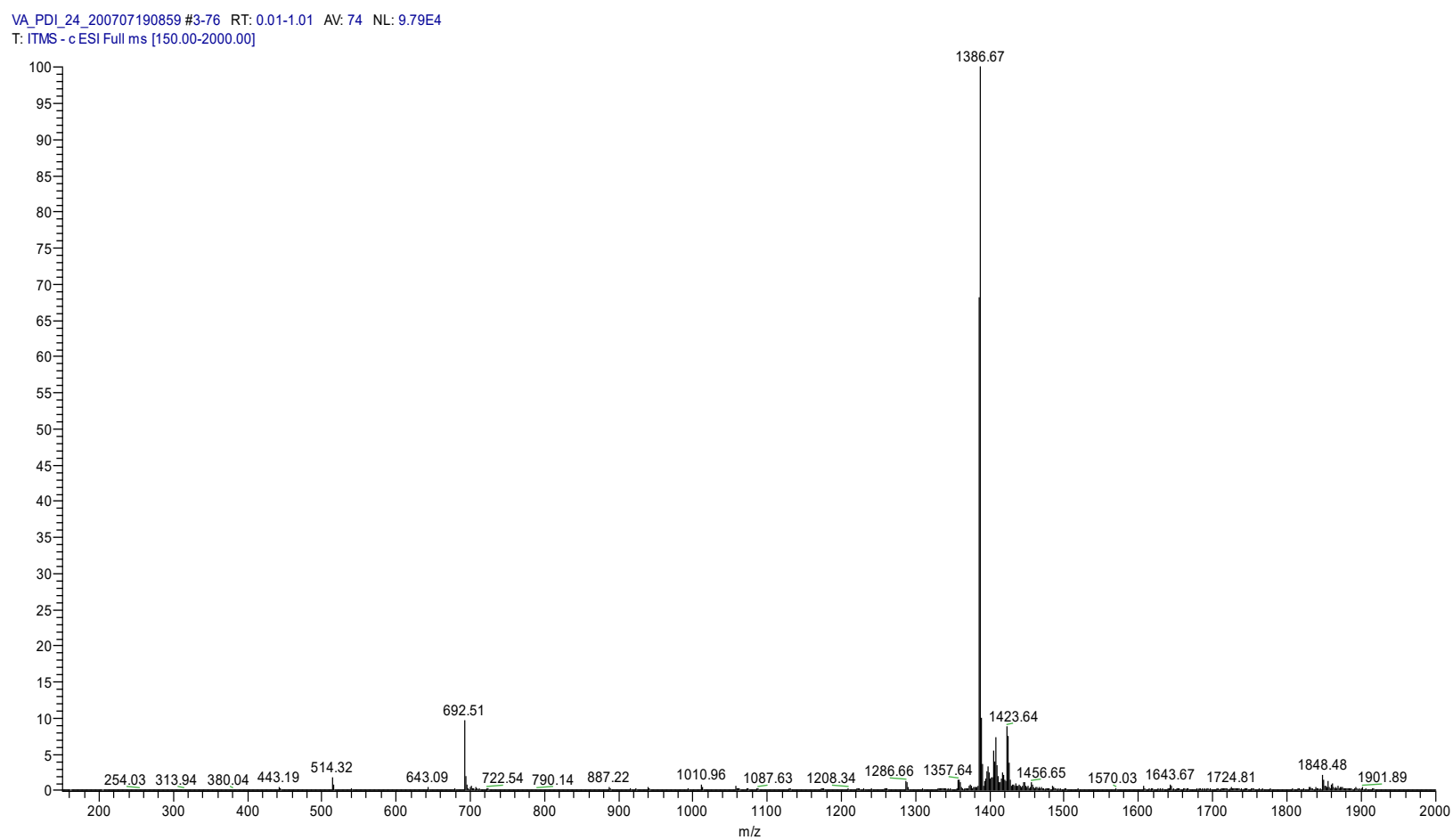

Figure S9. ESI- of VEVVA-PDI-AVVEV.

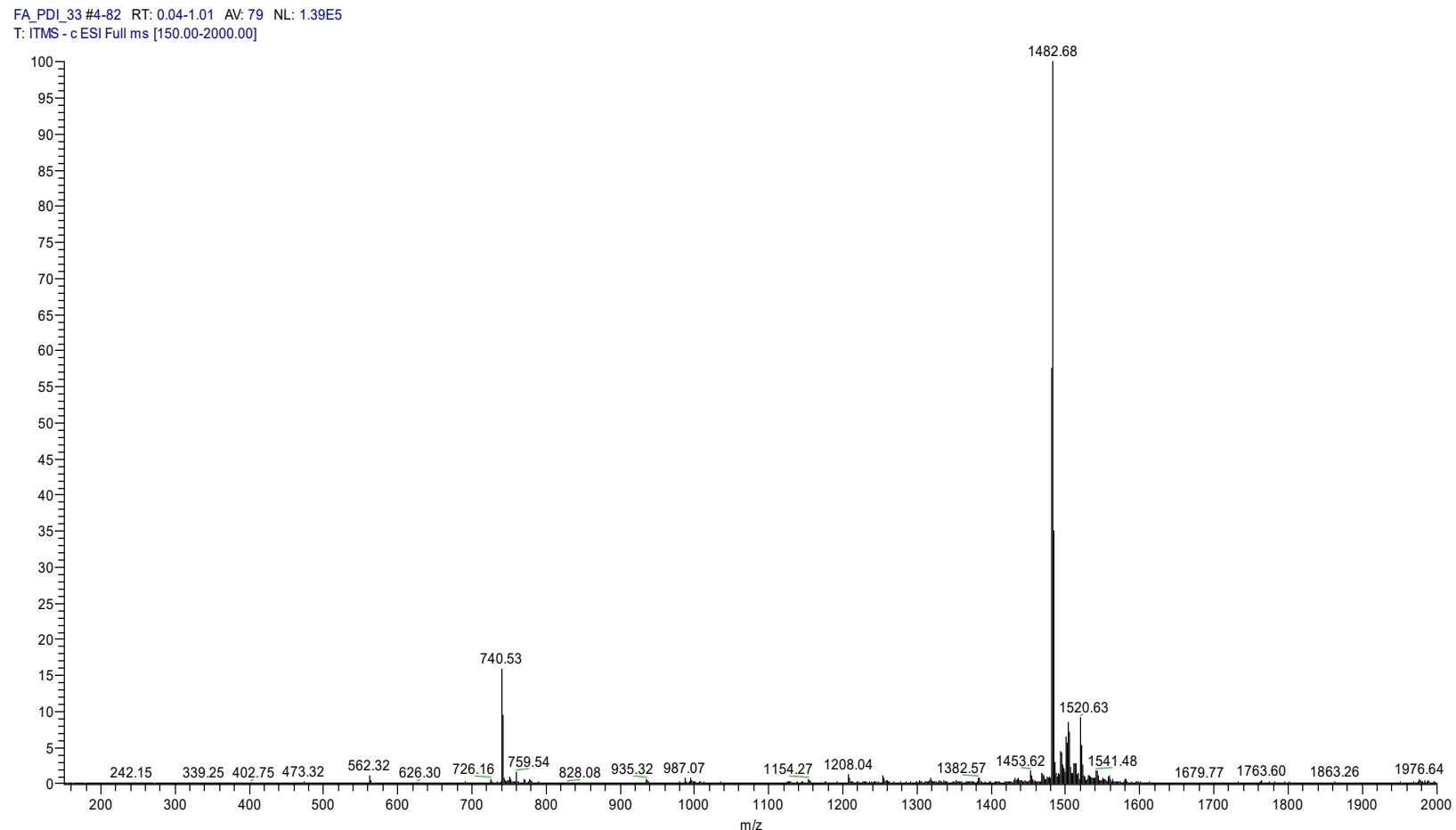

Figure S10. ESI- of VEVFA-PDI-AFVEV. 


\section{Analytical HPLC Traces}

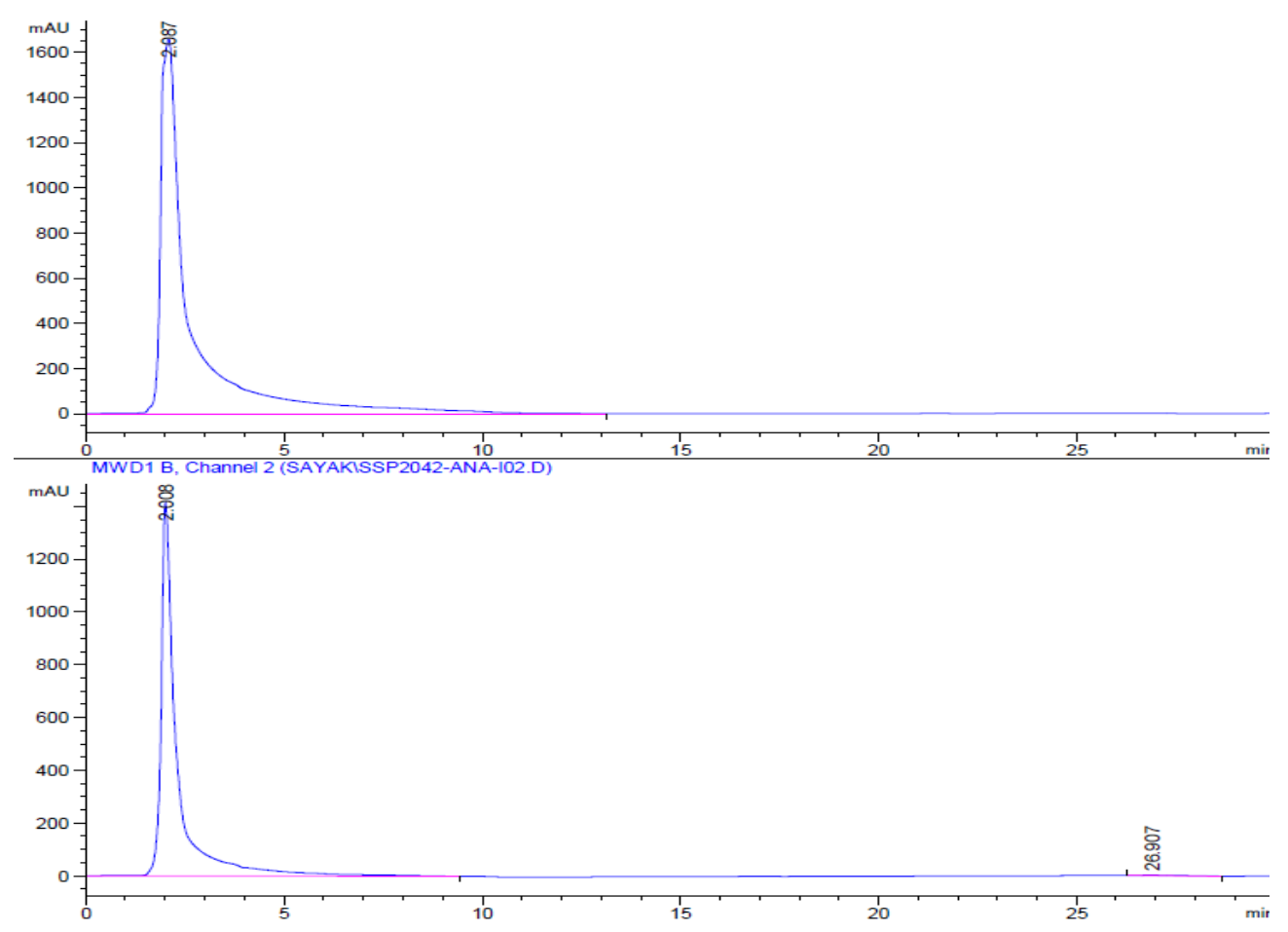

Figure S11. Analytical HPLC trace of DAVG-PDI-GVAD monitoring $260 \mathrm{~nm}$ (top) and $500 \mathrm{~nm}$ (bottom).

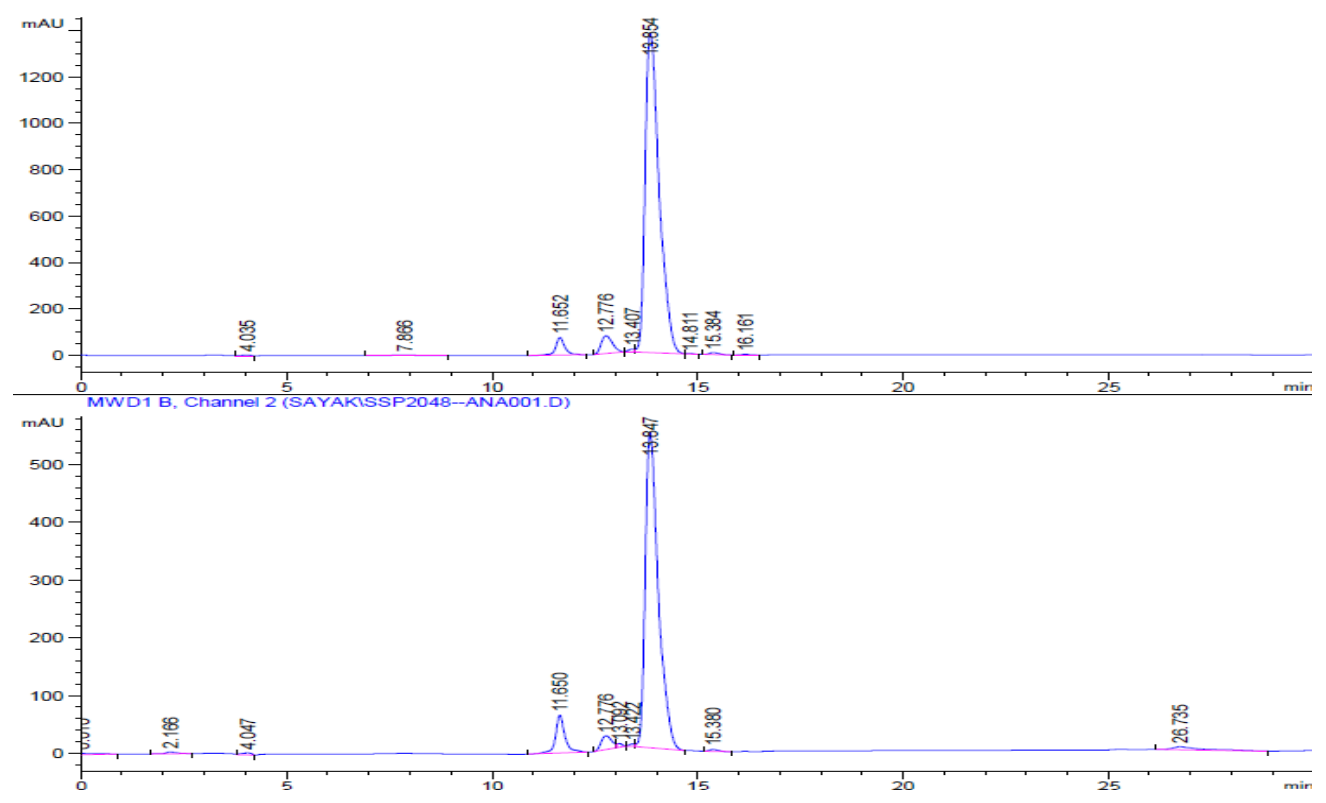

Figure S12. Analytical HPLC trace of DAIA-PDI-AIAD monitoring $260 \mathrm{~nm}$ (top) and $500 \mathrm{~nm}$ (bottom). 


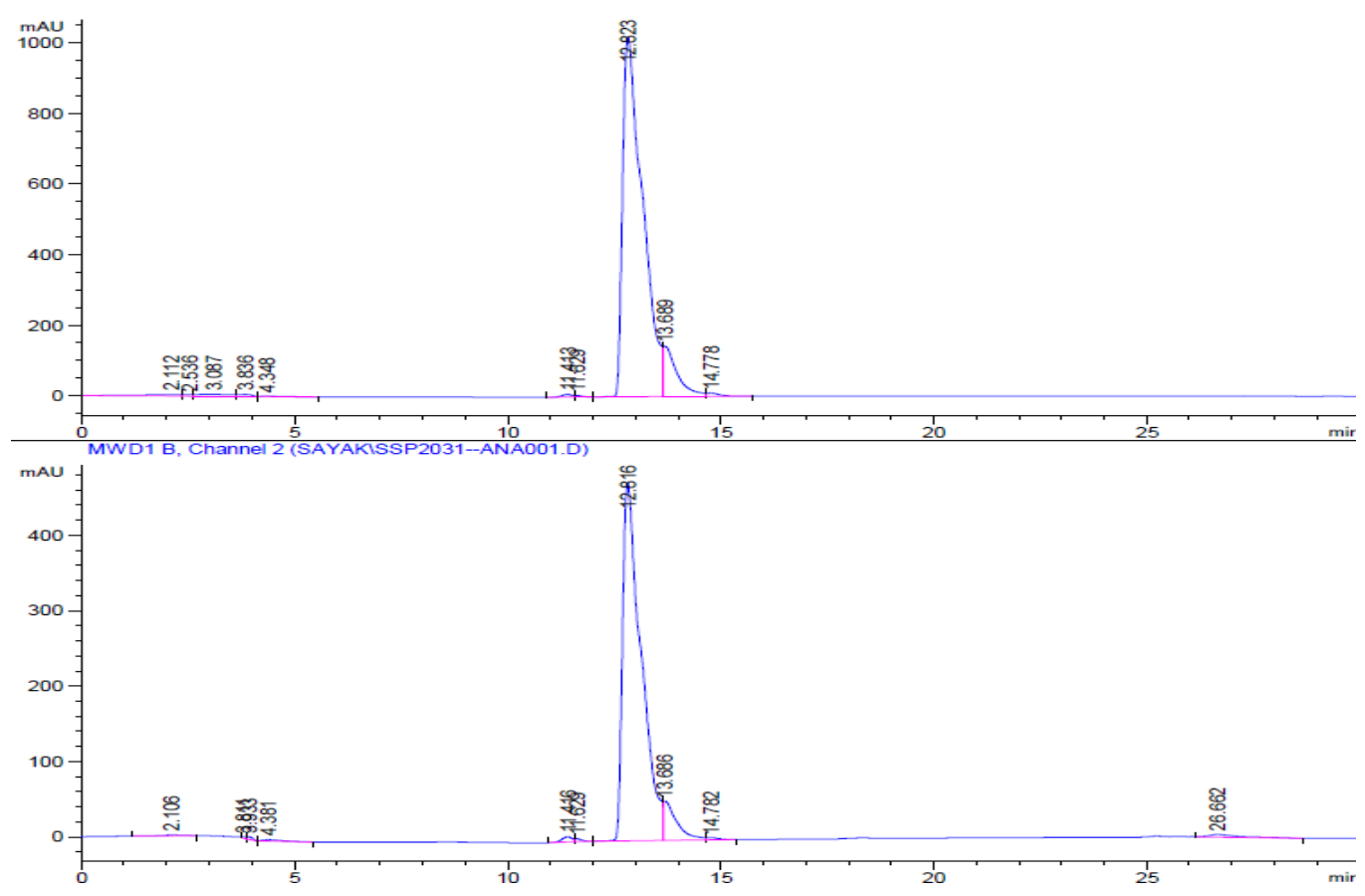

Figure S13. Analytical HPLC trace of VEVGG-PDI-GGVEV monitoring $260 \mathrm{~nm}$ (top) and 500 nm (bottom).

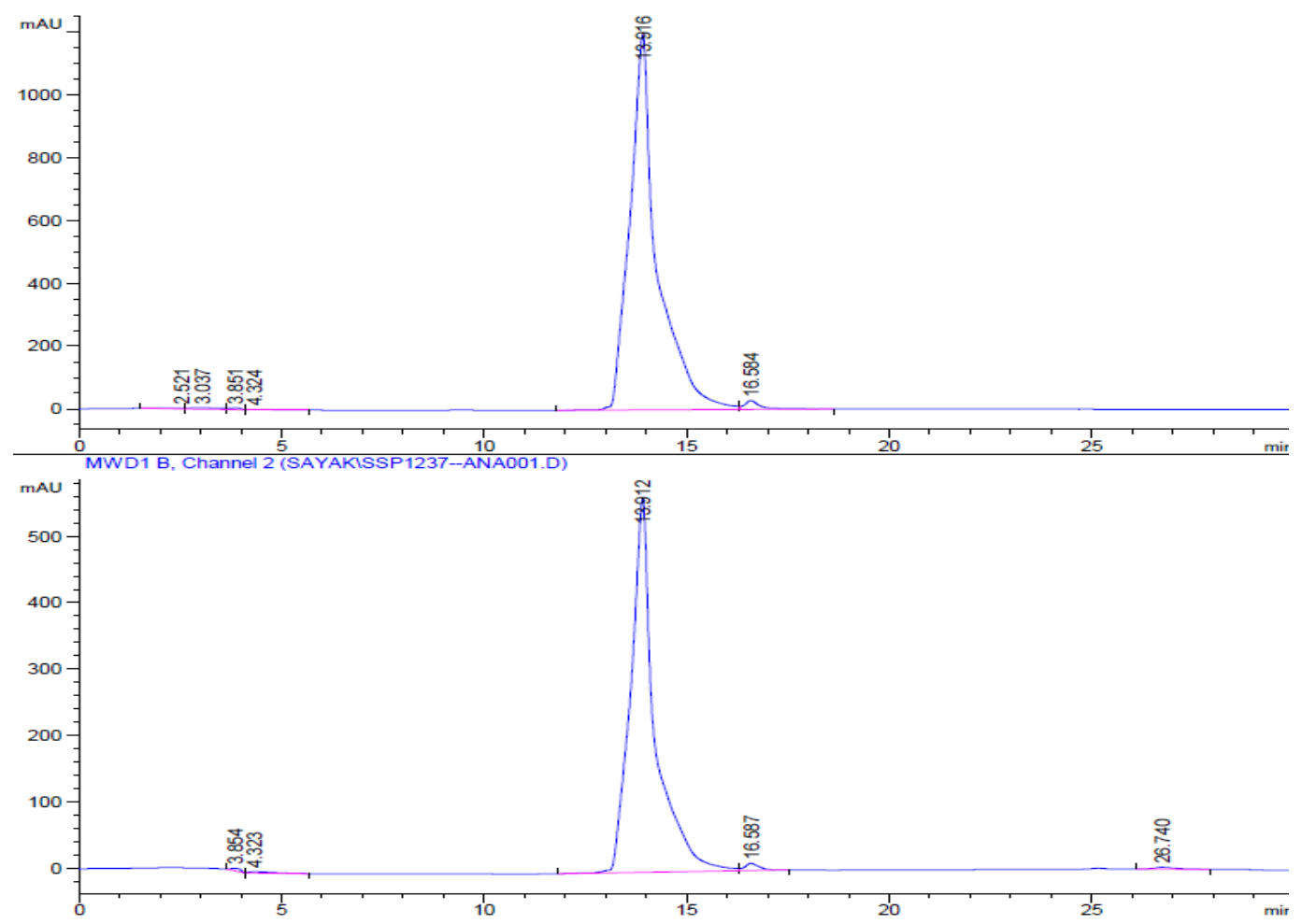

Figure S14. Analytical HPLC trace of VEVAG-PDI-GAVEV monitoring $260 \mathrm{~nm}$ (top) and 500 nm (bottom). 


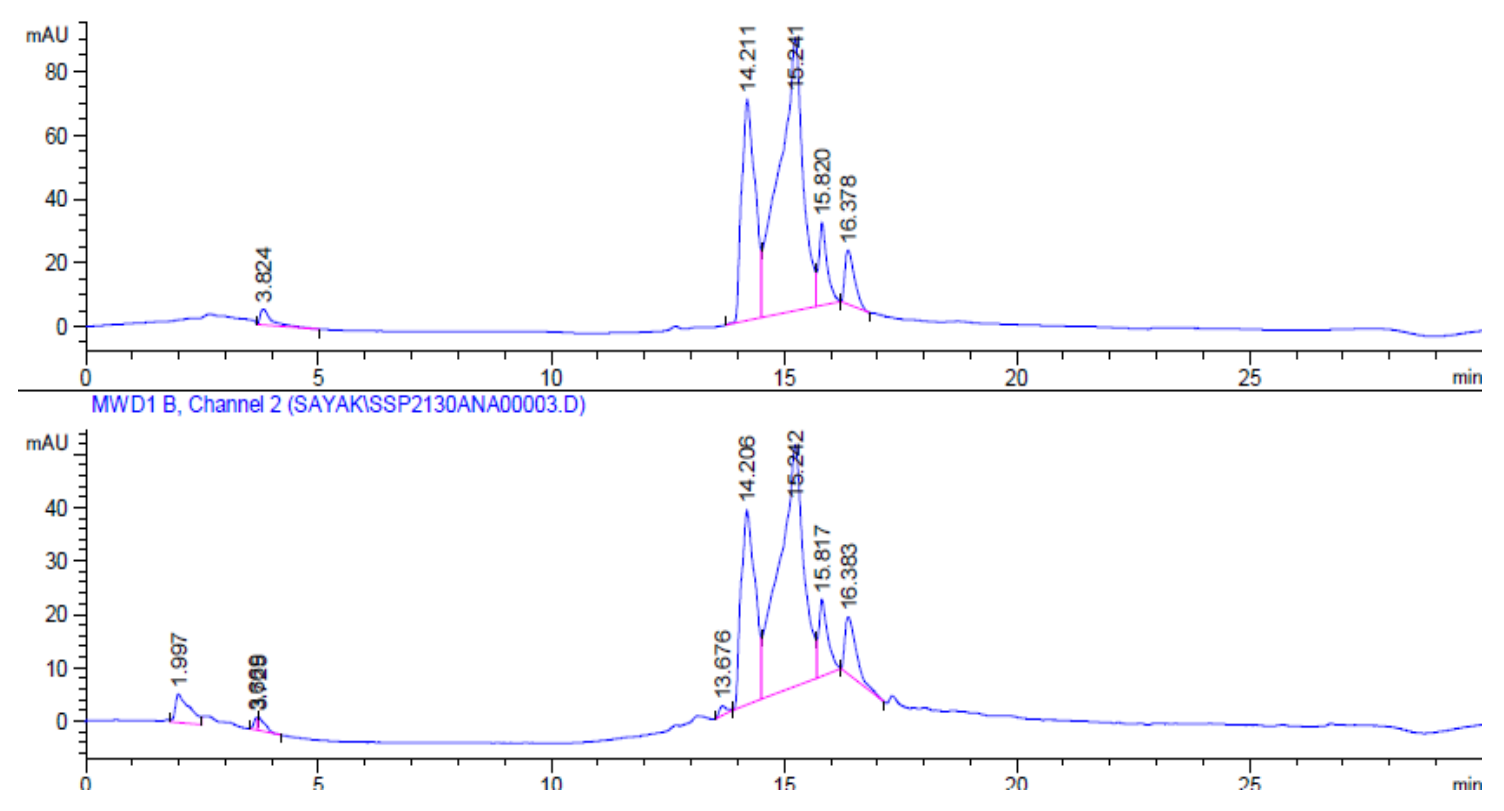

Figure S15. Analytical HPLC trace of VEVVG-PDI-GVVEV monitoring $260 \mathrm{~nm}$ (top) and 500 $\mathrm{nm}$ (bottom).

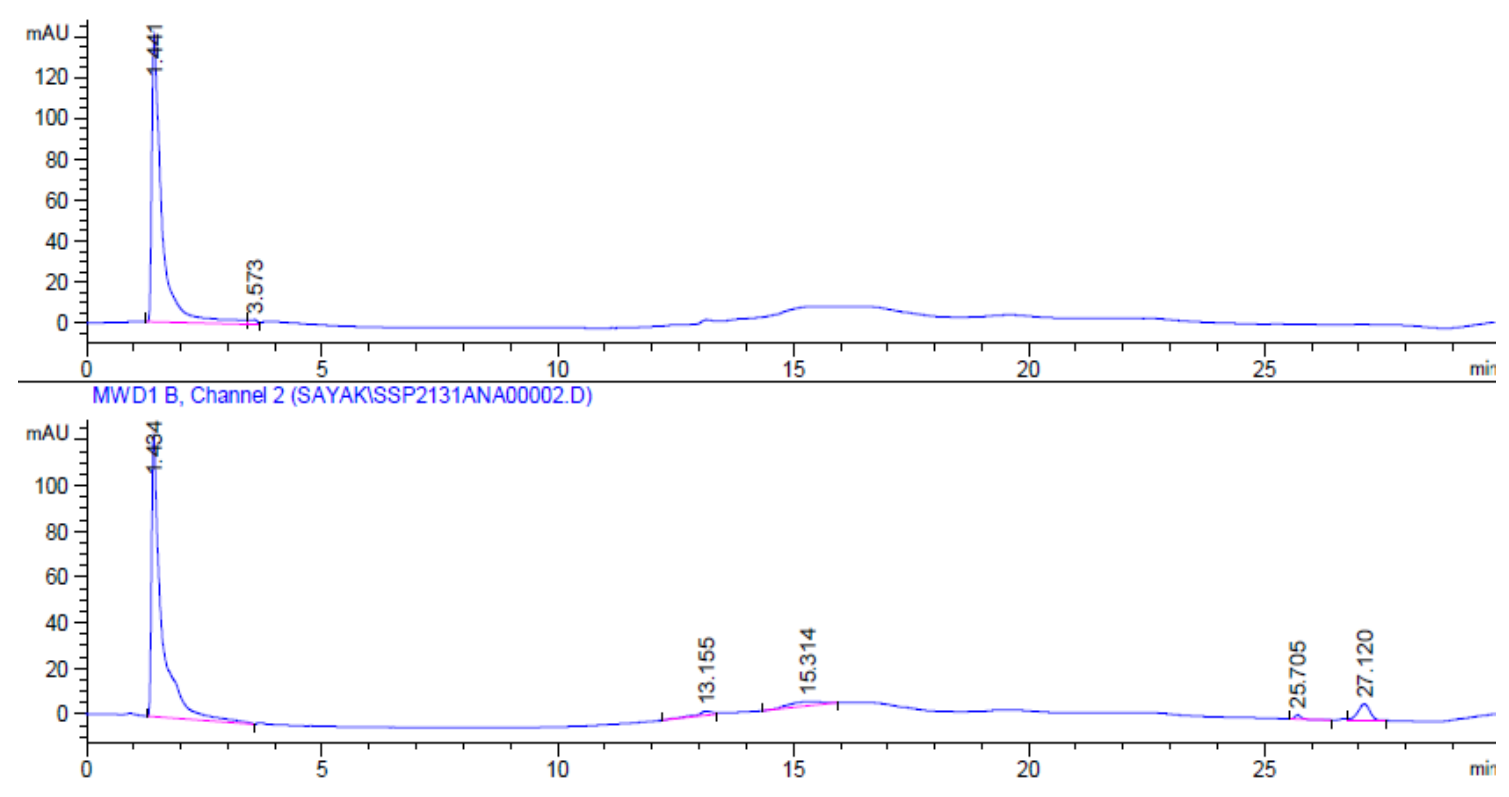

Figure S16. Analytical HPLC trace of VEVFG-PDI-GFVEV monitoring $260 \mathrm{~nm}$ (top) and 500 nm (bottom). 


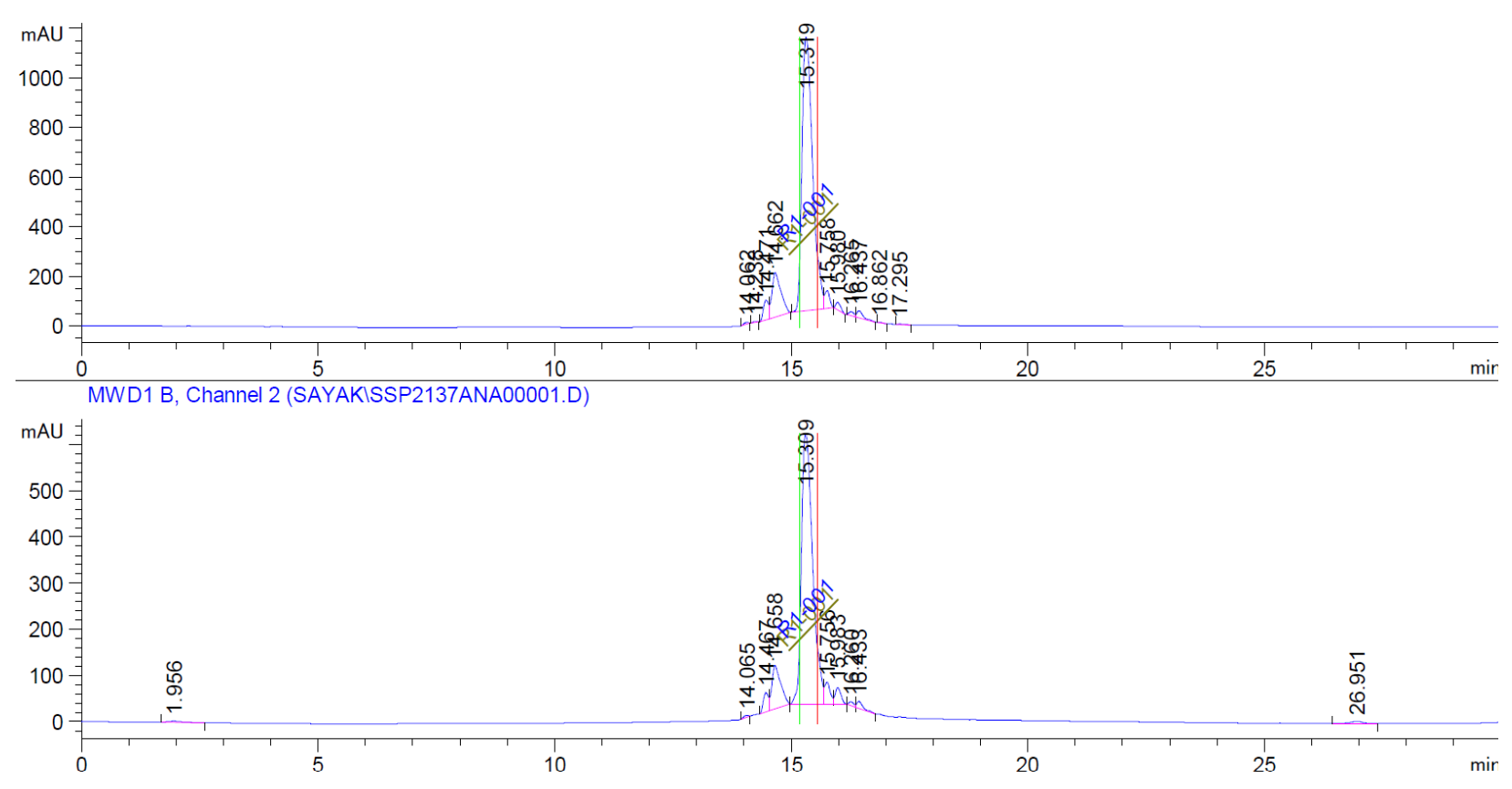

Figure S17. Analytical HPLC trace of VEVGA-PDI-AGVEV monitoring $260 \mathrm{~nm}$ (top) and 500 nm (bottom).

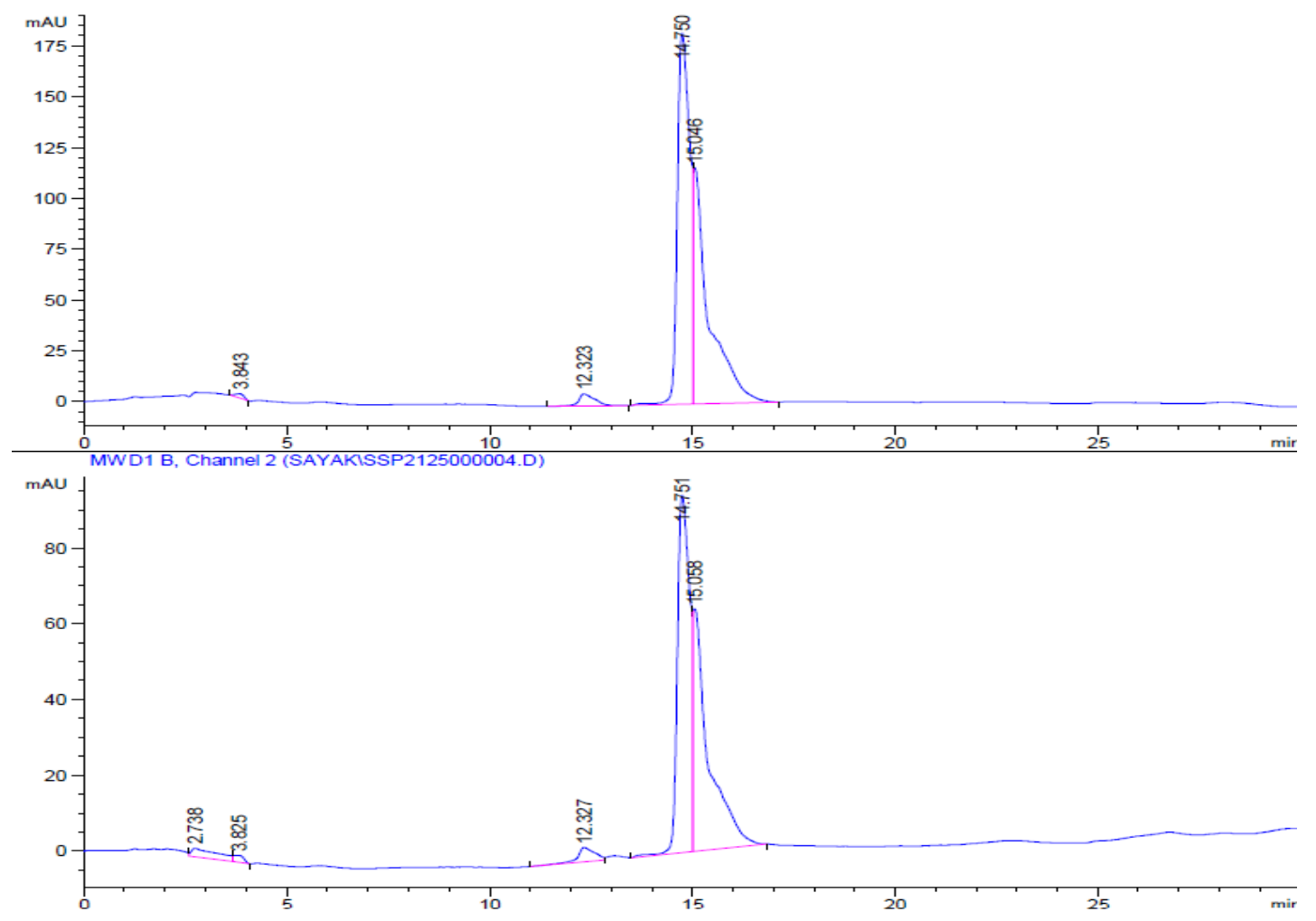

Figure S18. Analytical HPLC trace of VEVAA-PDI-AAVEV monitoring $260 \mathrm{~nm}$ (top) and 500 $\mathrm{nm}$ (bottom). 


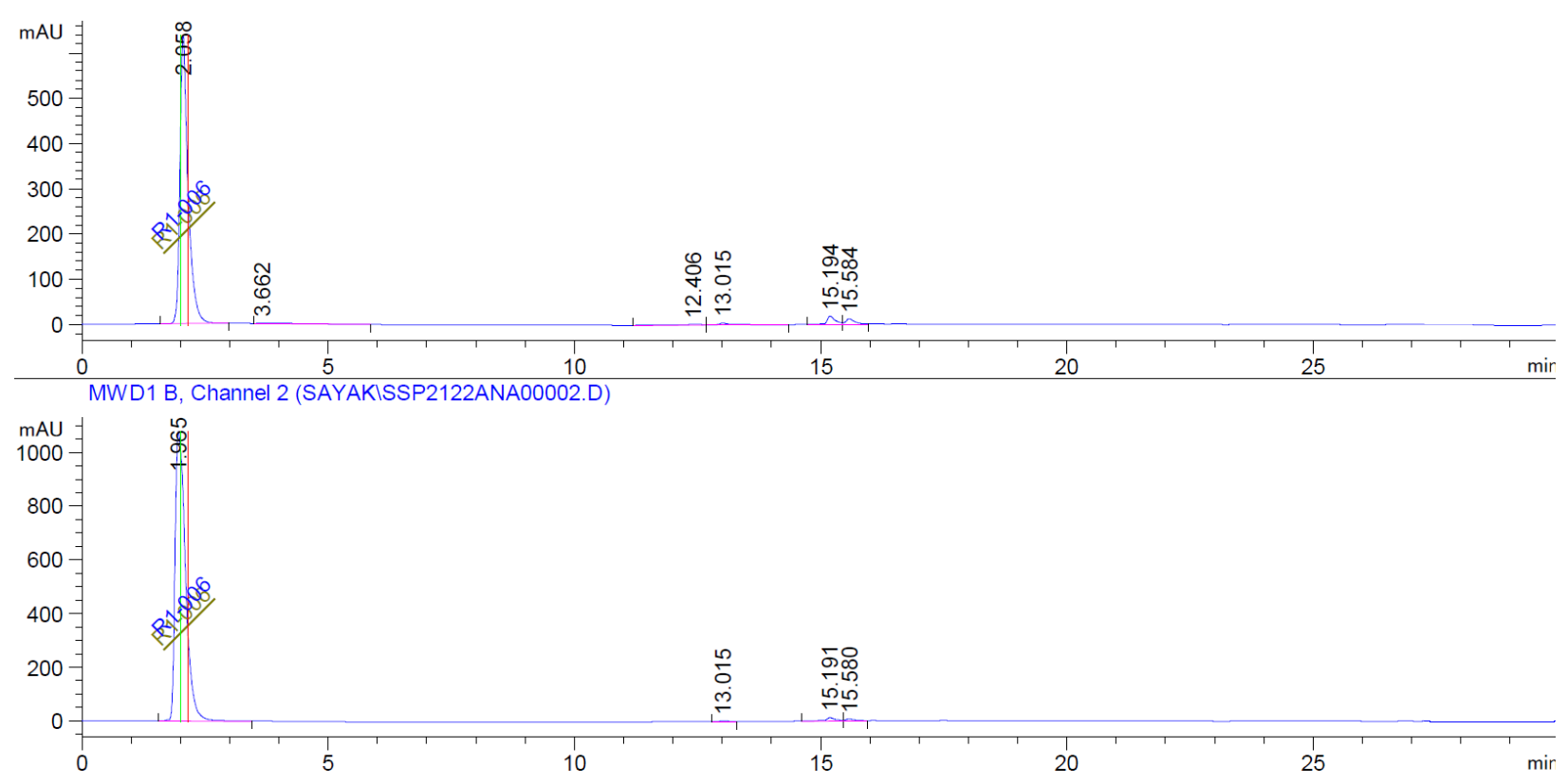

Figure S19. Analytical HPLC trace of VEVVA-PDI-AVVEV monitoring $260 \mathrm{~nm}$ (top) and 500 $\mathrm{nm}$ (bottom).

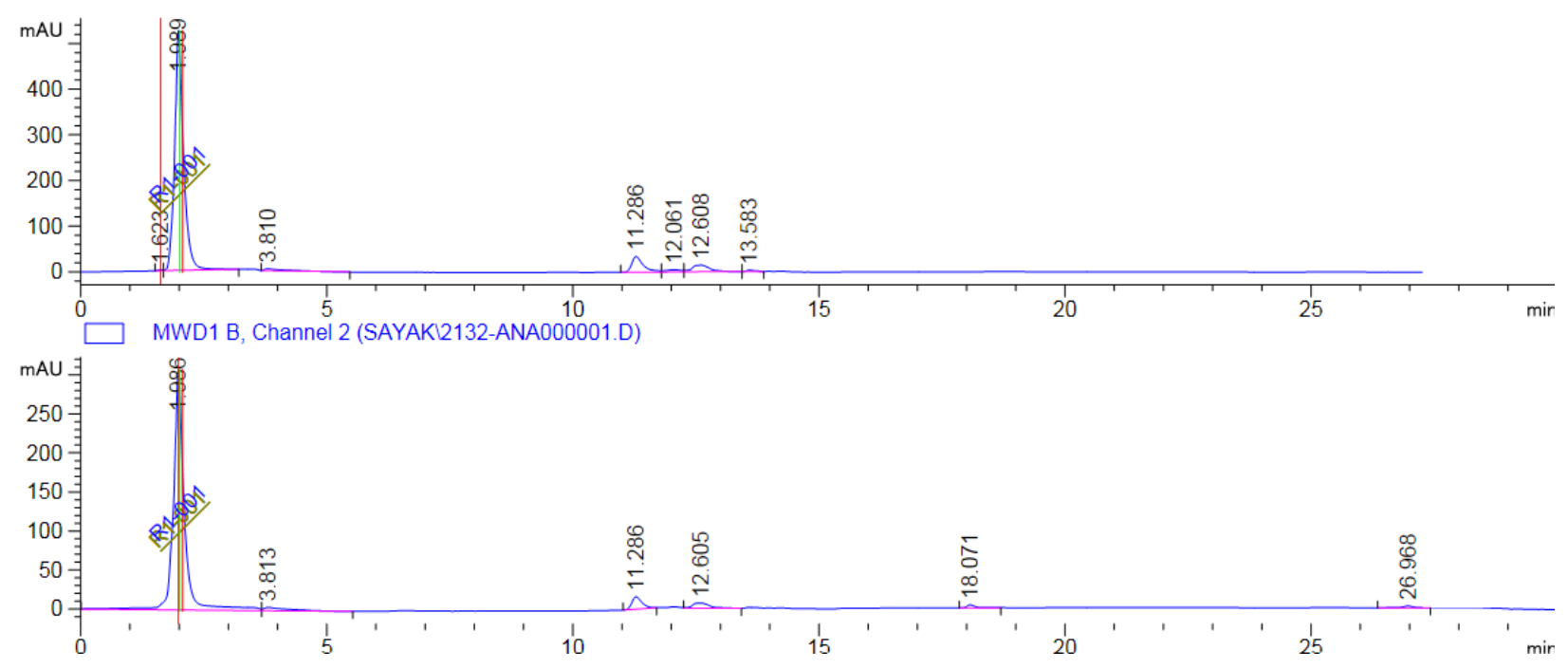

Figure S20. Analytical HPLC trace of VEVFA-PDI-AFVEV monitoring $260 \mathrm{~nm}$ (top) and 500 nm (bottom). 


\section{TEM Images}

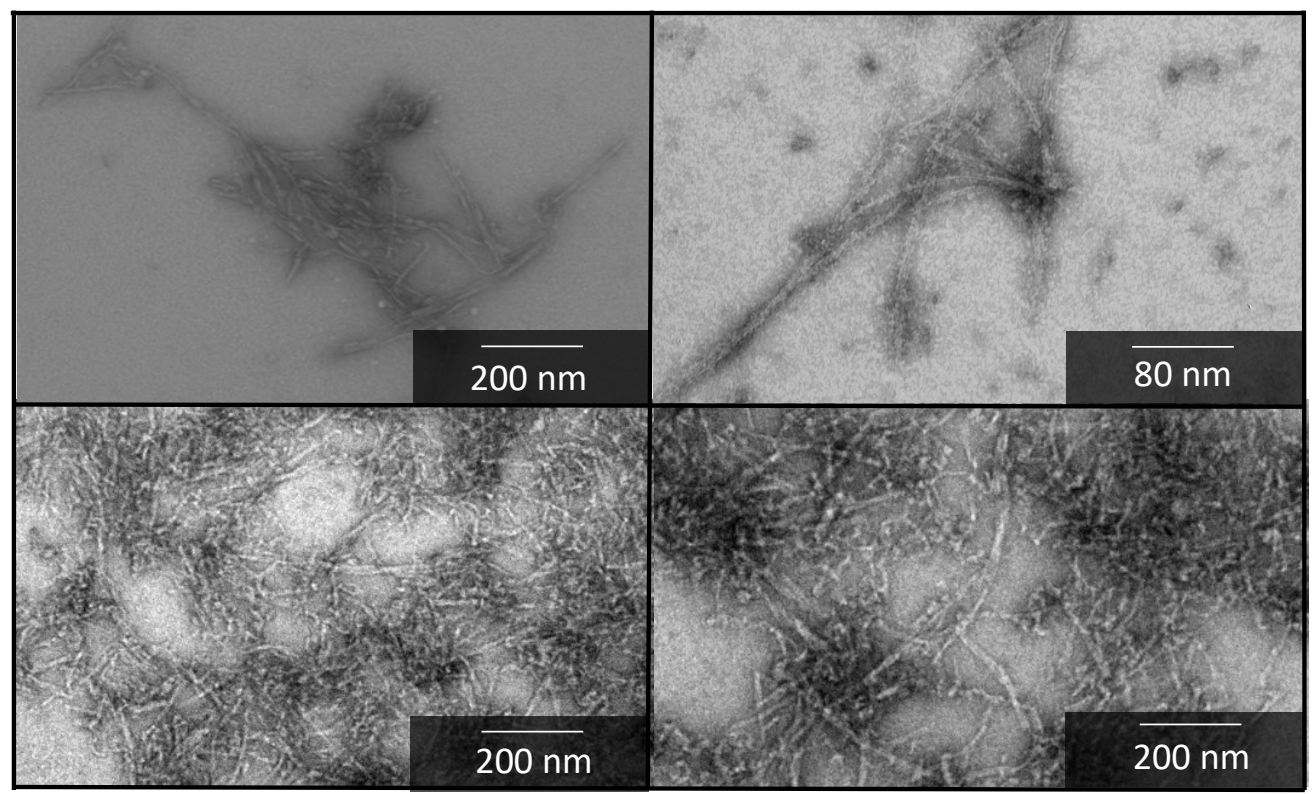

Figure S21. TEM images of peptide VEVGG-PDI-GGVEV (1st row, left; $11.3 \pm 0.8 \mathrm{~nm}$ ), VEVAG-PDI-GAVEV (1st row, right; $8.8 \pm 0.9 \mathrm{~nm}$ ), VEVVG-PDI-GVVEV (2nd row, right; $12.3 \pm 0.6 \mathrm{~nm}$ ), VEVFG-PDI-GFVEV (2nd row, left; $12.6 \pm 0.7 \mathrm{~nm}$ ). Nanostructure widths are mentioned in parentheses.

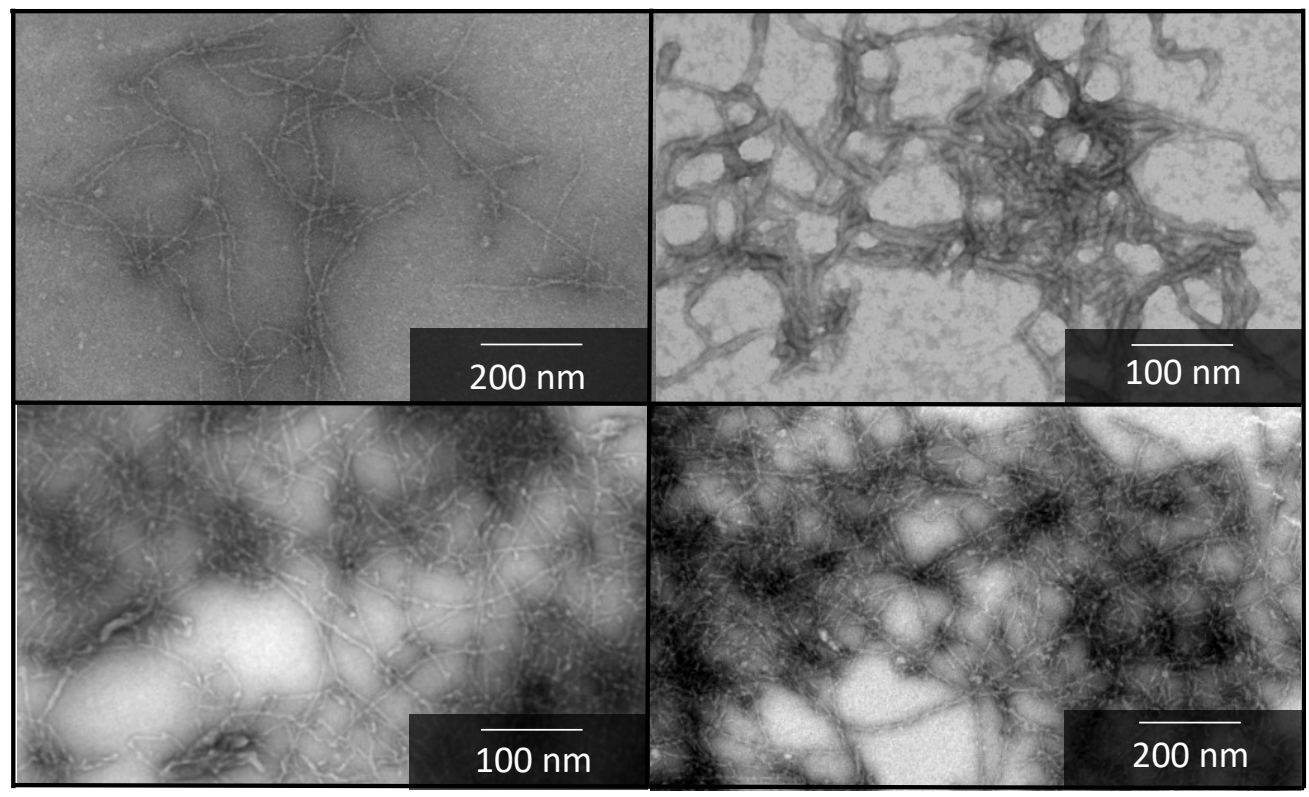

Figure S22. TEM images of peptide VEVGA-PDI-AGVEV (1st row, left; $13.6 \pm 0.8 \mathrm{~nm}$ ), VEVAA-PDI-AAVEV (1st row, right; $14.5 \pm 0.7 \mathrm{~nm}$ ), VEVVA-PDI-AVVEV (2nd row, right; $13.1 \pm 0.7 \mathrm{~nm}$ ), VEVFA-PDI-AFVEV (2nd row, left; $12.9 \pm 0.6 \mathrm{~nm}$ ). Nanostructure widths are mentioned in parentheses. 


\section{DLS}
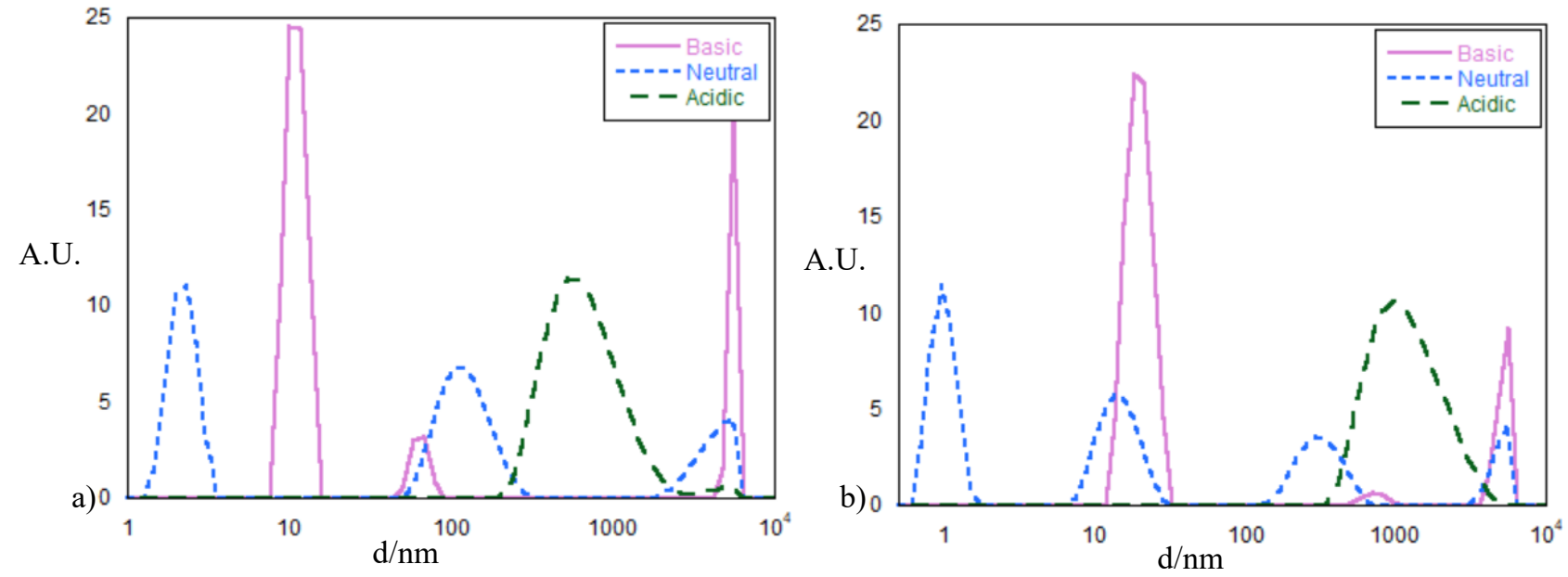

Figure S23. Dynamic Light Scattering of peptide a) DAVG-PDI-GVAD (left), b) DAIA-PDIAIAD (right).
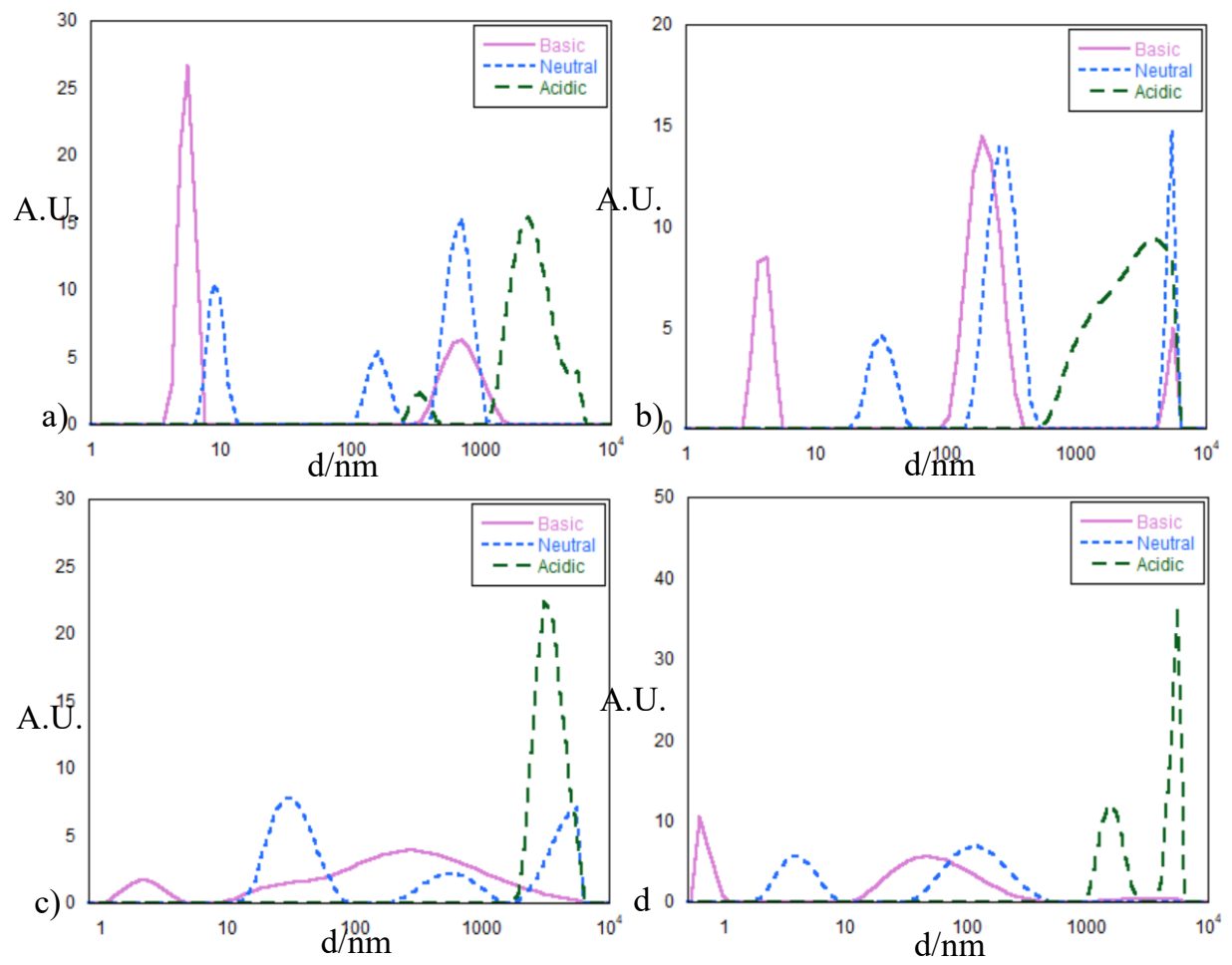

Figure S24. Dynamic Light Scattering of peptide a) VEVGG-PDI-GGVEV (1st row, left), b) VEVAG-PDI-GAVEV (1 st row, right), c) VEVVG-PDI-GVVEV (2nd row, right), d) VEVFGPDI-GFVEV (2nd row, left). 

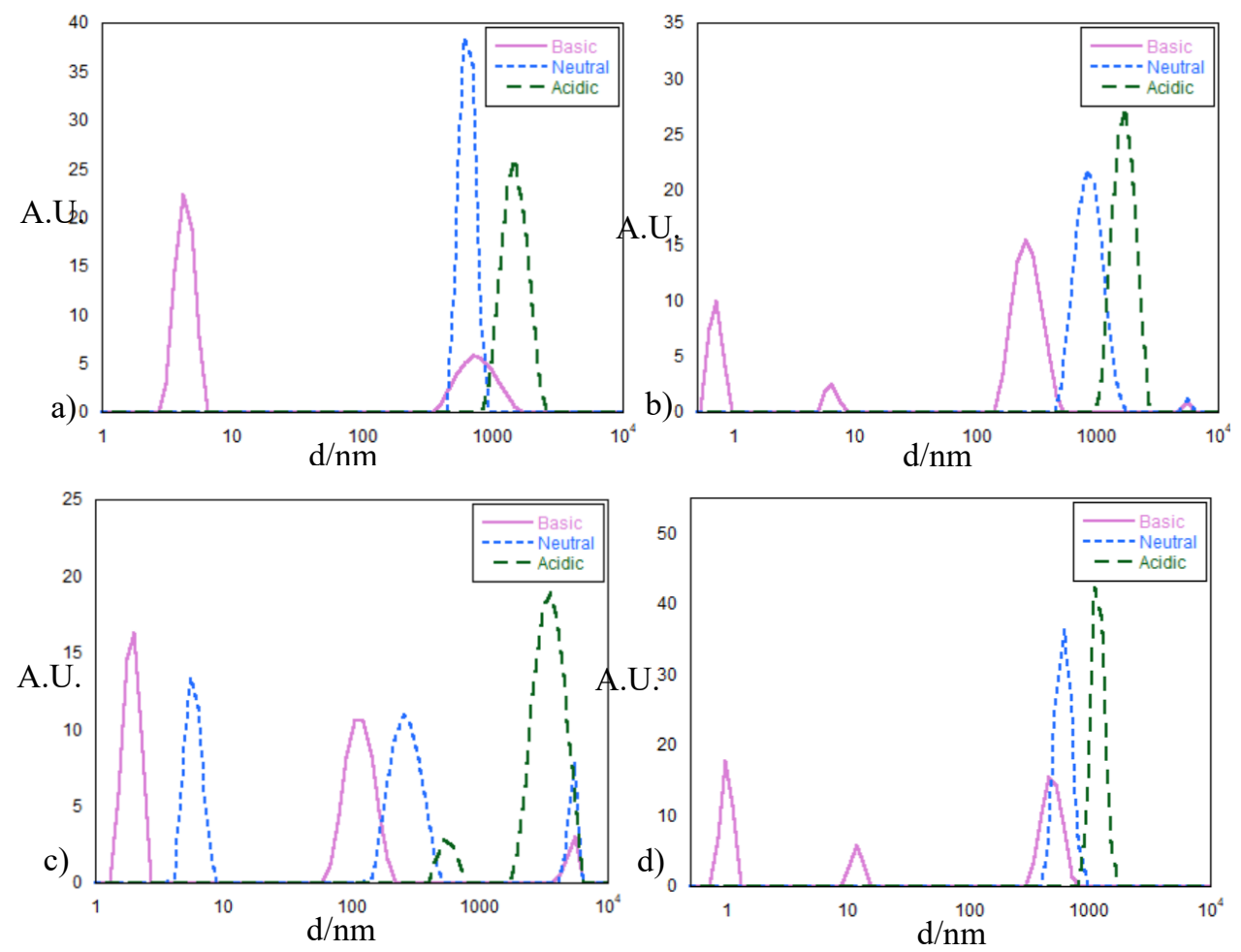

Figure S25. Dynamic Light Scattering of peptide a) VEVGA-PDI-AGVEV (1st row, left), b) VEVAA-PDI-AAVEV (1st row, right), c) VEVVA-PDI-AVVEV (2nd row, right), d) VEVFAPDI-AFVEV (2nd row, left). 


\section{FT-IR Spectra}
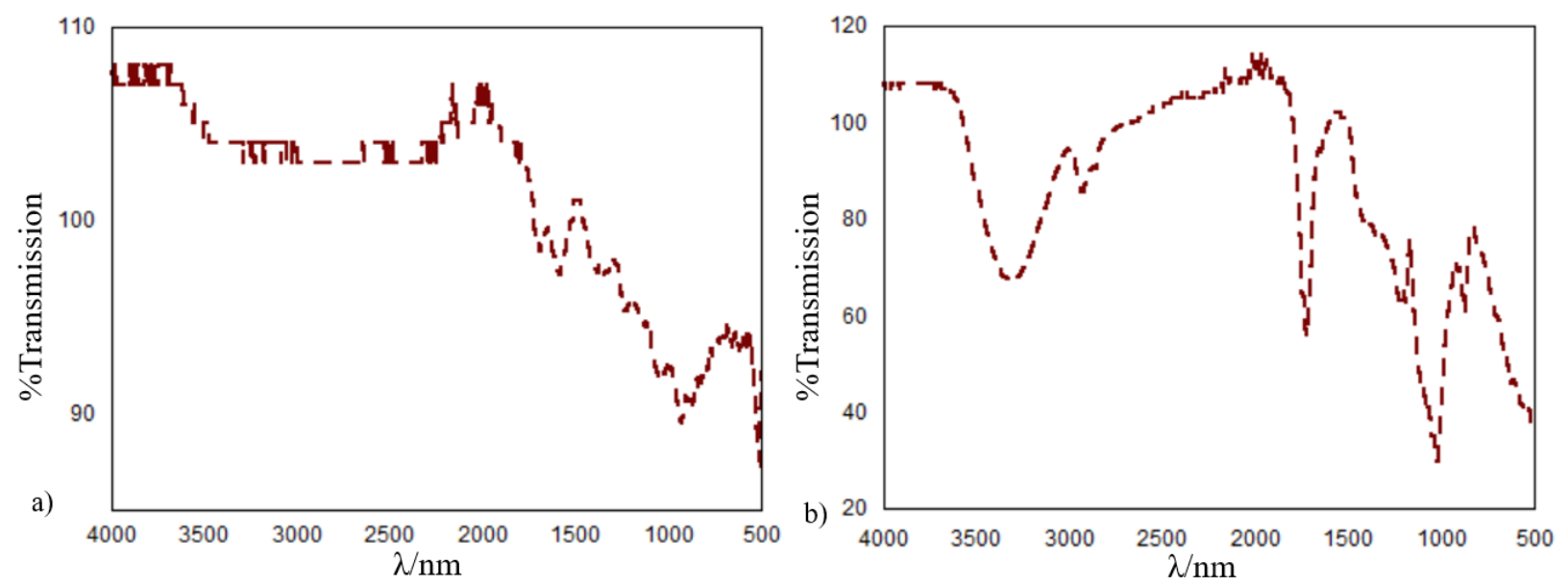

Figure S26. FT-IR spectra of lyophilized acidic solution of a) DAVG-PDI-GVAD, and b) DAIAPDI-AIAD.
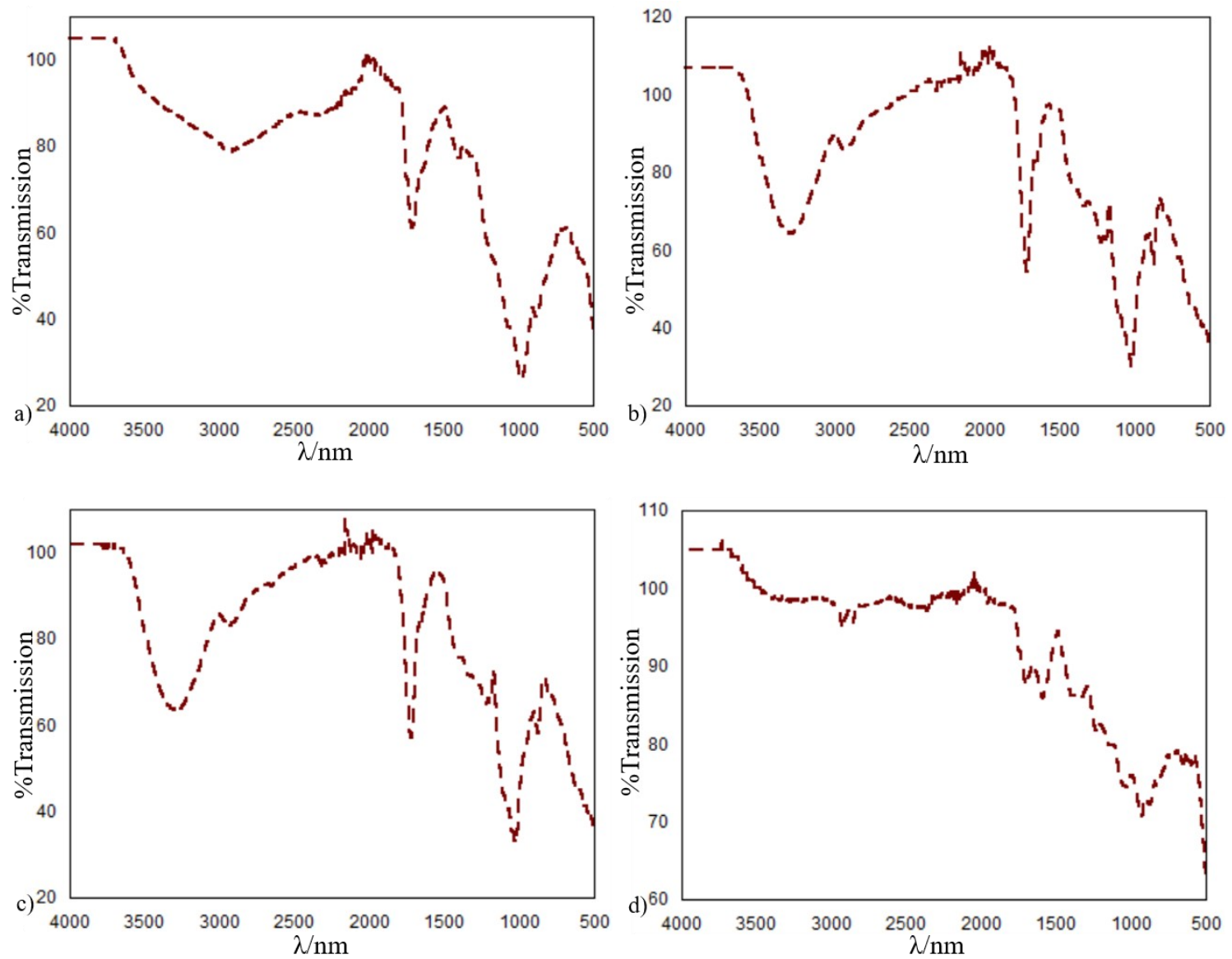

Figure S27. FT-IR spectra of lyophilized acidic solution of a) VEVGG-PDI-GGVEV (1st row, left), b) VEVAG-PDI-GAVEV (1st row, right), c) VEVVG-PDI-GVVEV (2nd row, right), d) VEVFG-PDI-GFVEV (2nd row, left). 

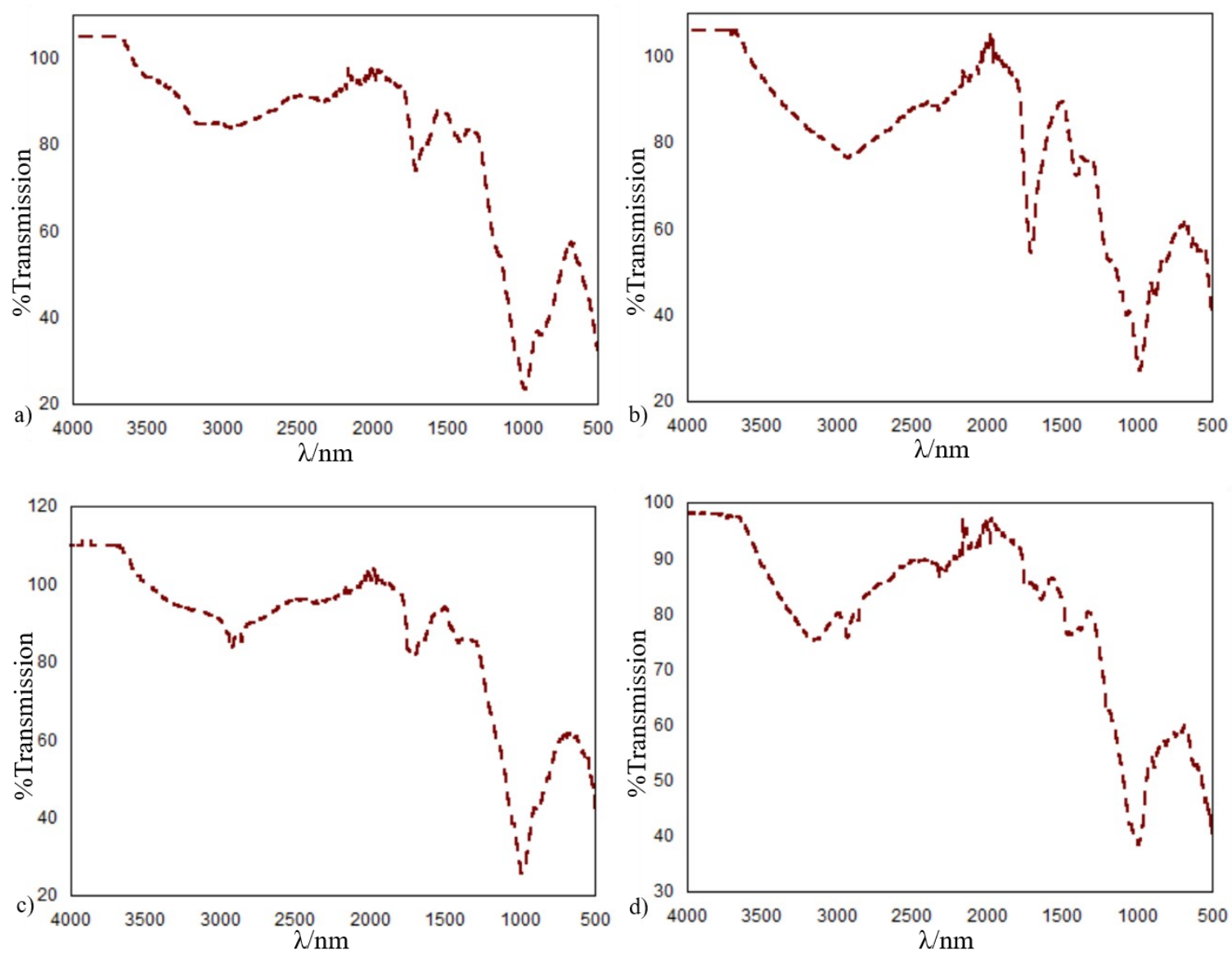

Figure S28. FT-IR spectra of lyophilized acidic solution of a) VEVGA-PDI-AGVEV (1st row, left), b) VEVAA-PDI-AAVEV (1st row, right), c) VEVVA-PDI-AVVEV (2nd row, right), d) VEVFA-PDI-AFVEV (2nd row, left). 


\section{UV-Vis Spectra}
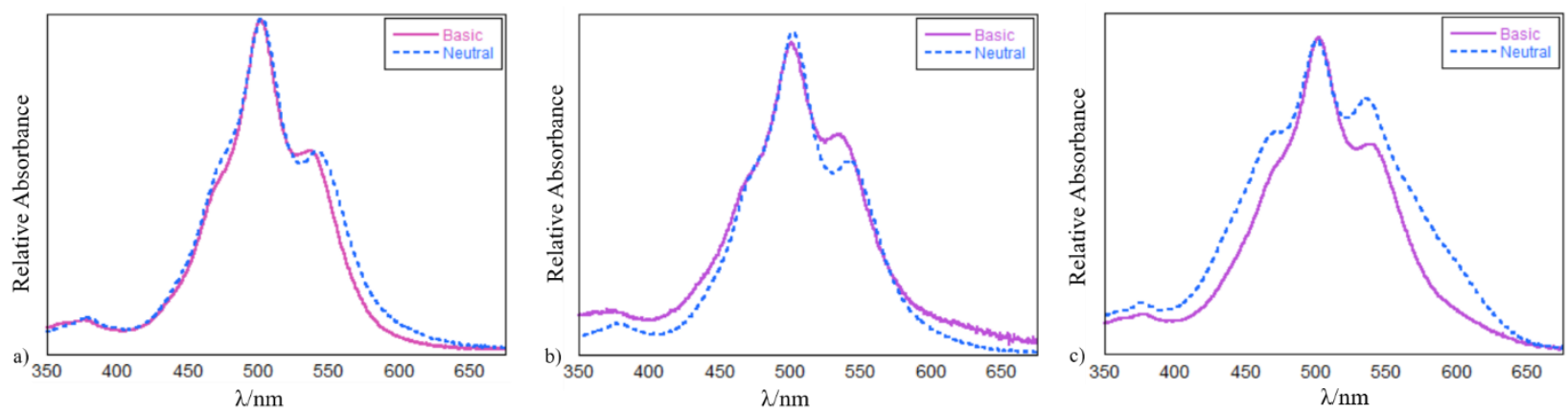

Figure S29. UV-Vis signatures of a) VEVGG, b) VEVVG, c) VEVFG under basic and neutral conditions. All the spectra were recorded at 5-7.5 $\mu \mathrm{M}$ concentration range.
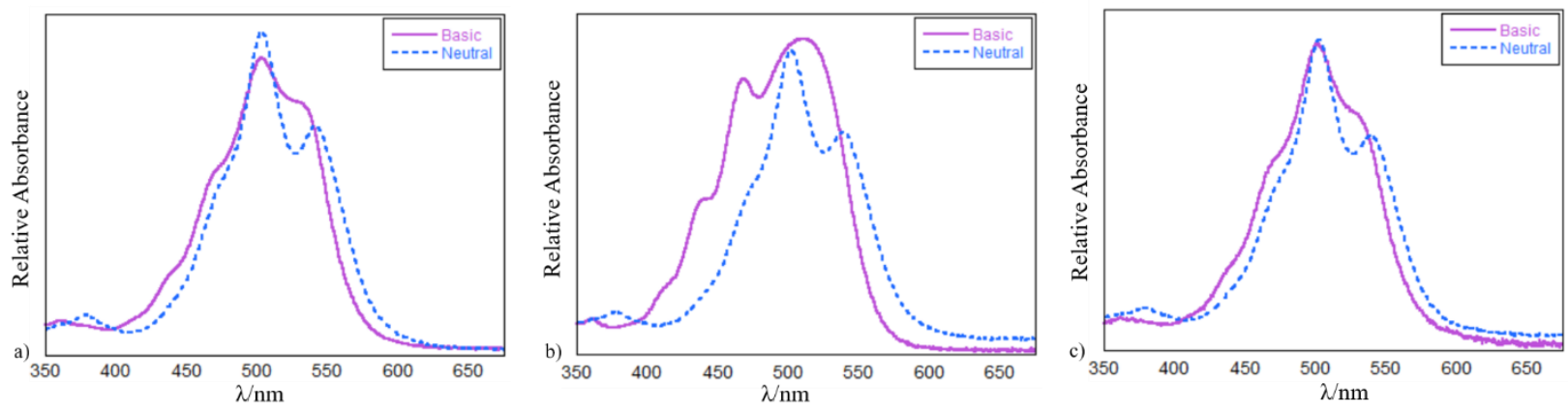

Figure S30. UV-Vis signatures of a) VEVGA, b) VEVVA, c) VEVFA under basic and neutral conditions. All the spectra were recorded at 5-7.5 $\mu \mathrm{M}$ concentration range. 


\section{PL Spectra}
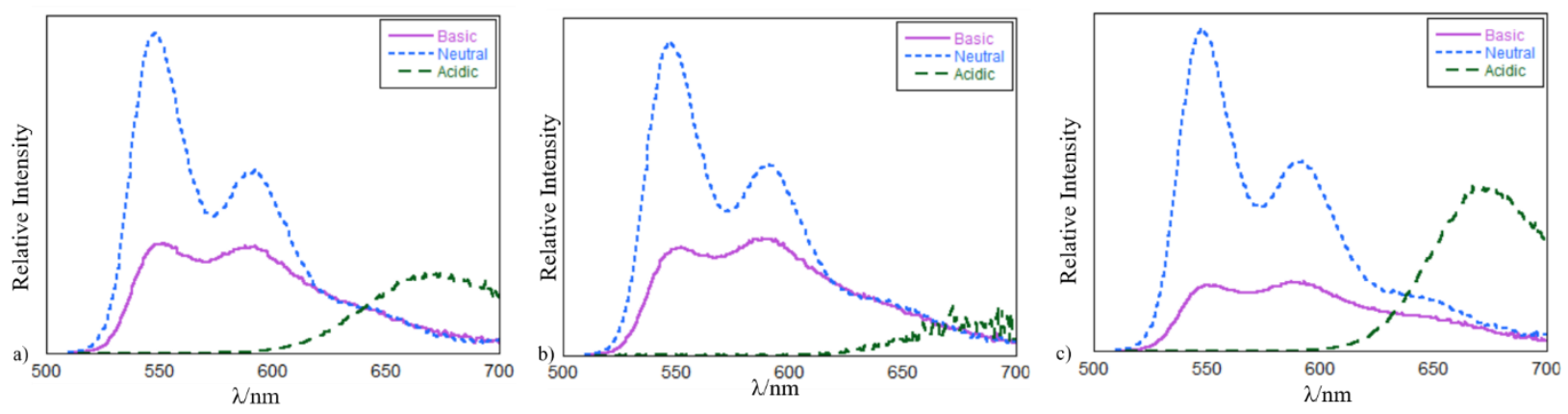

Figure S31. PL Spectroscopy of a) VEVGG, b) VEVVG, c) VEVFG under basic, neutral, and acidic conditions. All the spectra were recorded at 5-7.5 $\mu \mathrm{M}$ concentration range.
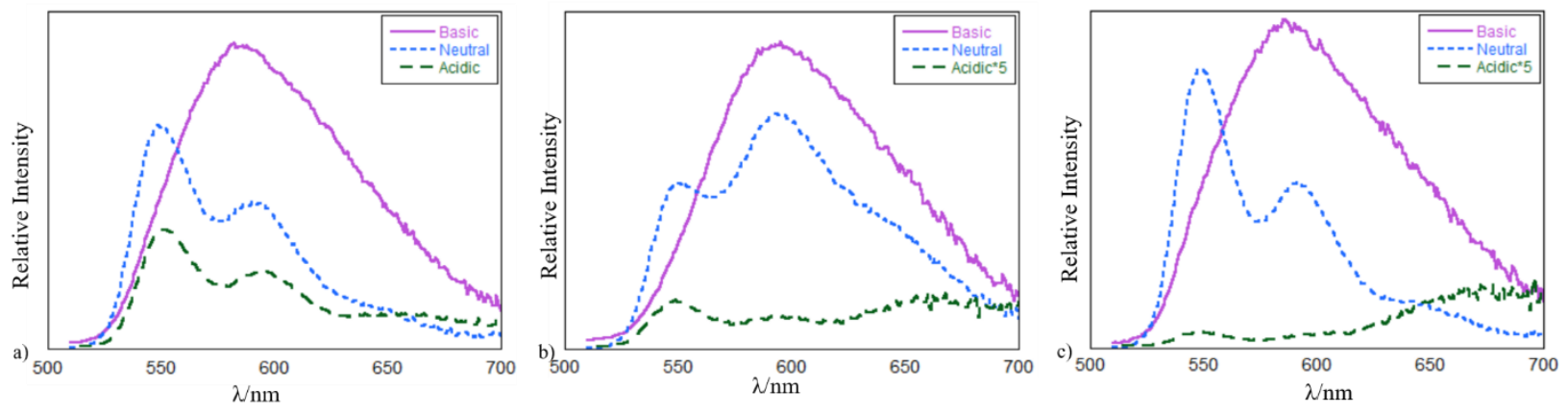

Figure S32. PL Spectroscopy of a) VEVGA, b) VEVVA, c) VEVFA under basic, neutral, and acidic conditions. All the spectra were recorded at 5-7.5 $\mu \mathrm{M}$ concentration range. 


\section{Spectra}
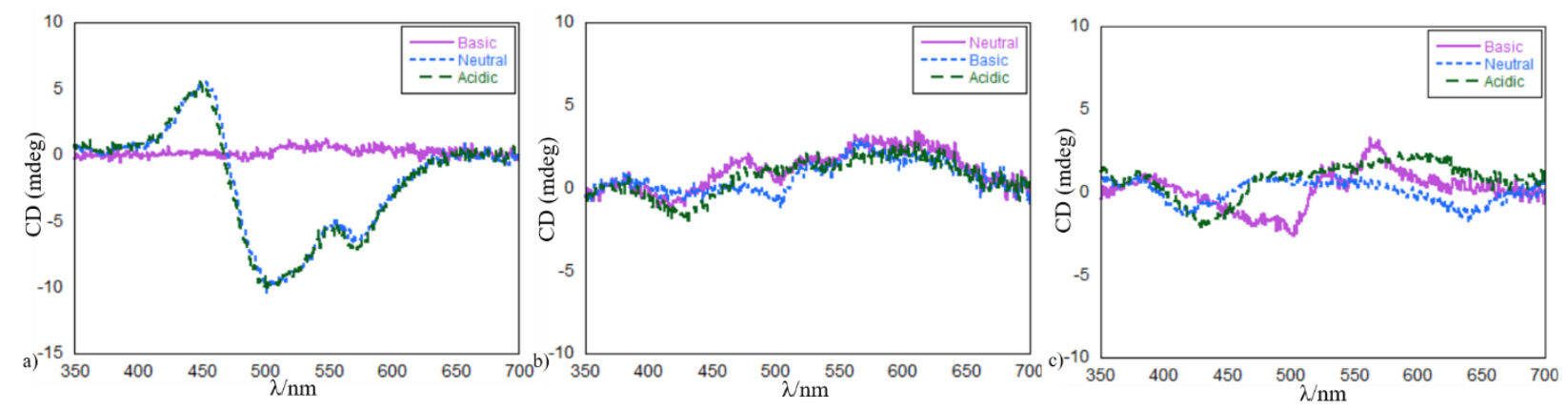

Figure S33. CD Spectroscopy of a) VEVGG, b) VEVVG, c) VEVFG under basic, neutral, and acidic conditions. All the spectra were recorded at 15-20 $\mu \mathrm{M}$ concentration range.
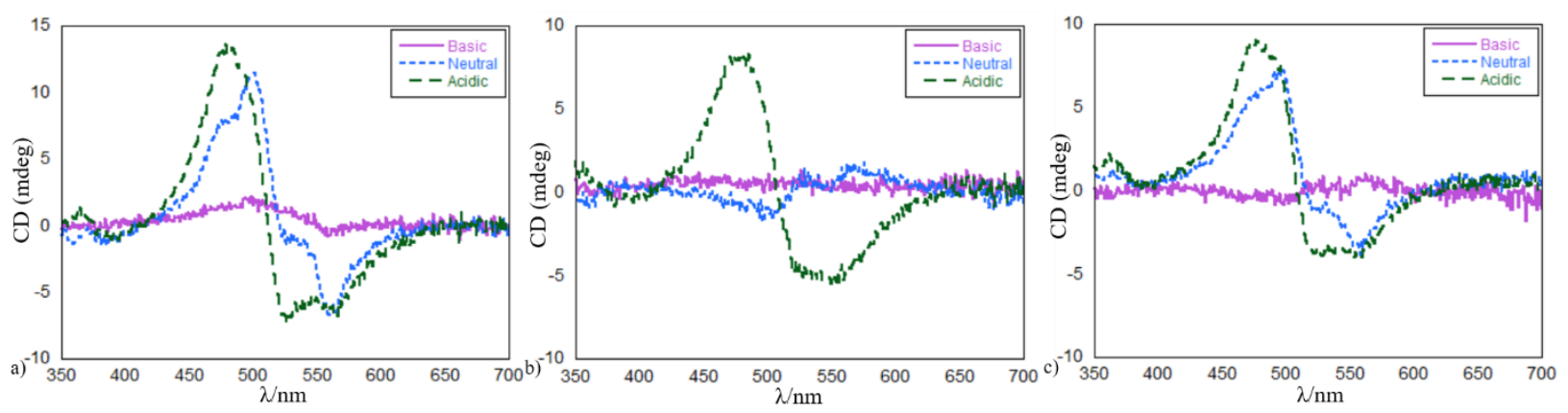

Figure S34. CD Spectroscopy of a) VEVGA, b) VEVVA, c) VEVFA under basic, neutral, and acidic conditions. All the spectra were recorded at 15-20 $\mu \mathrm{M}$ concentration range. 